\title{
Cancer nanomedicine: a review of recent success in drug delivery
}

\author{
Stephanie $\operatorname{Tran}^{1 \dagger}$, Peter-Joseph DeGiovanni ${ }^{1,2+}$, Brandon Piel $^{2+}$ and Prakash Rai ${ }^{2 *}$
}

\begin{abstract}
Cancer continues to be one of the most difficult global healthcare problems. Although there is a large library of drugs that can be used in cancer treatment, the problem is selectively killing all the cancer cells while reducing collateral toxicity to healthy cells. There are several biological barriers to effective drug delivery in cancer such as renal, hepatic, or immune clearance. Nanoparticles loaded with drugs can be designed to overcome these biological barriers to improve efficacy while reducing morbidity. Nanomedicine has ushered in a new era for drug delivery by improving the therapeutic indices of the active pharmaceutical ingredients engineered within nanoparticles. First generation nanomedicines have received widespread clinical approval over the past two decades, from Doxil ${ }^{\circledR}$ (liposomal doxorubicin) in 1995 to Onivyde ${ }^{\circledR}$ (liposomal irinotecan) in 2015. This review highlights the biological barriers to effective drug delivery in cancer, emphasizing the need for nanoparticles for improving therapeutic outcomes. A summary of different nanoparticles used for drug delivery applications in cancer are presented. The review summarizes recent successes in cancer nanomedicine in the clinic. The clinical trials of Onivyde leading to its approval in 2015 by the Food and Drug Adminstration are highlighted as a case study in the recent clinical success of nanomedicine against cancer. Next generation nanomedicines need to be better targeted to specifically destroy cancerous tissue, but face several obstacles in their clinical development, including identification of appropriate biomarkers to target, scale-up of synthesis, and reproducible characterization. These hurdles need to be overcome through multidisciplinary collaborations across academia, pharmaceutical industry, and regulatory agencies in order to achieve the goal of eradicating cancer. This review discusses the current use of clinically approved nanomedicines, the investigation of nanomedicines in clinical trials, and the challenges that may hinder development of the nanomedicines for cancer treatment.
\end{abstract}

Keywords: Nanoparticles, Oncology, Clinical trials, Therapeutics, Combination treatment, Theranostics, MM-398

\section{Background}

Cancer is currently among one of the leading causes of deaths worldwide, with $1,688,780$ new cases and 600,920 cancer deaths projected for 2017. Over the next 20 years, the number of new cases is projected to increase by about $70 \%$ [1]. Current treatments may include chemotherapy, radiation, and surgery, but the effects of these procedures may damage not only the tumor tissue but also normal tissue. Weinberg and Hanahan have described a set of six hallmarks of cancer, which may help distinguish

\footnotetext{
*Correspondence: prakash_rai@uml.edu

†Stephanie Tran, Peter-Joseph DeGiovanni and Brandon Piel contributed equally to this work

2 Department of Chemical Engineering, University of Massachusetts, 1

University ave, Lowell, MA 01854, USA

Full list of author information is available at the end of the article
}

characteristics between the normal and tumor tissue and perhaps provide better alternative treatments. These hallmarks include sustaining proliferative signaling, evading growth suppressors, activating invasion and metastasis, enabling replicative immortality, inducing angiogenesis, and resisting cell death [2]. Even in the absence of injury or development, cancer cells can maintain growth signals and continue proliferation. Normal regulators of cell growth and apoptosis are often inhibited. High levels of telomerase may help cancer cells maintain the integrity of their DNA and thus allow them to replicate infinitely. The formation of new blood vessels, or angiogenesis, is a method for cancer cells to obtain nutrients and remove waste. Cancer cells can also migrate to new sites and form new, secondary tumors. Two emerging hallmarks of cancer include reprogramming energy metabolism and 
evading immune destruction. Cancer cells have upregulated glucose transporter expression, and they tend to reprogram their metabolic pathway to "aerobic glycolysis". This metabolic switch may allow the generation of nucleosides and amino acids, which facilitate additional growth and proliferation. Markers that T-lymphocytes use to recognize and destroy foreign or abnormal cells are not well-expressed by cancer cells, thus allowing them to avoid elimination by the immune system [2].

Since the characterization of cancer via these hallmarks of cancer, new methods for treatment have been investigated. Nanomedicine can be defined as nanotechnology, or the use of materials between 1 and $100 \mathrm{~nm}$, applied to health and medicine [3]. Nanomedicine is an emerging method for treating cancer. Current problems in treating cancer include low specificity, rapid drug clearance and biodegradation, and limited targeting [4]. The properties of nanocarriers, including their nanoscale sizes, high surface-to-volume ratios, favorable drug release profiles, and targeting modifications, can allow them to better reach target tumor tissue and release drugs in a stable, controlled manner [3]. Nanocarriers can accumulate in leaky vasculature, which is a characteristic of tumor tissue, in an effect known as the enhanced permeability and retention effect (EPR) effect [5]. Use of internal and external stimuli as well as targeting modifications may assist in the controlled release of the drug to ensure specific toxicity to the tumor tissue, while sparing normal tissue. The poor solubility of small molecule drugs often restricts their delivery to the tumor, and therefore encapsulating the drugs in nanocarriers may facilitate travel through the bloodstream, thus preventing rapid clearance and improving bioavailability. The potential of nanomedicines can be further extended to early detection of cancers as well as combination therapies that can start treating tumors earlier and more effectively. Currently, a wide variety of platforms are being investigated as nanocarriers for cancer treatment, including lipid-based, polymer-based, inorganic, viral, and drugconjugated nanoparticles (Fig. 1). Several of these same platforms have also been approved for use in the clinic (Table 1).

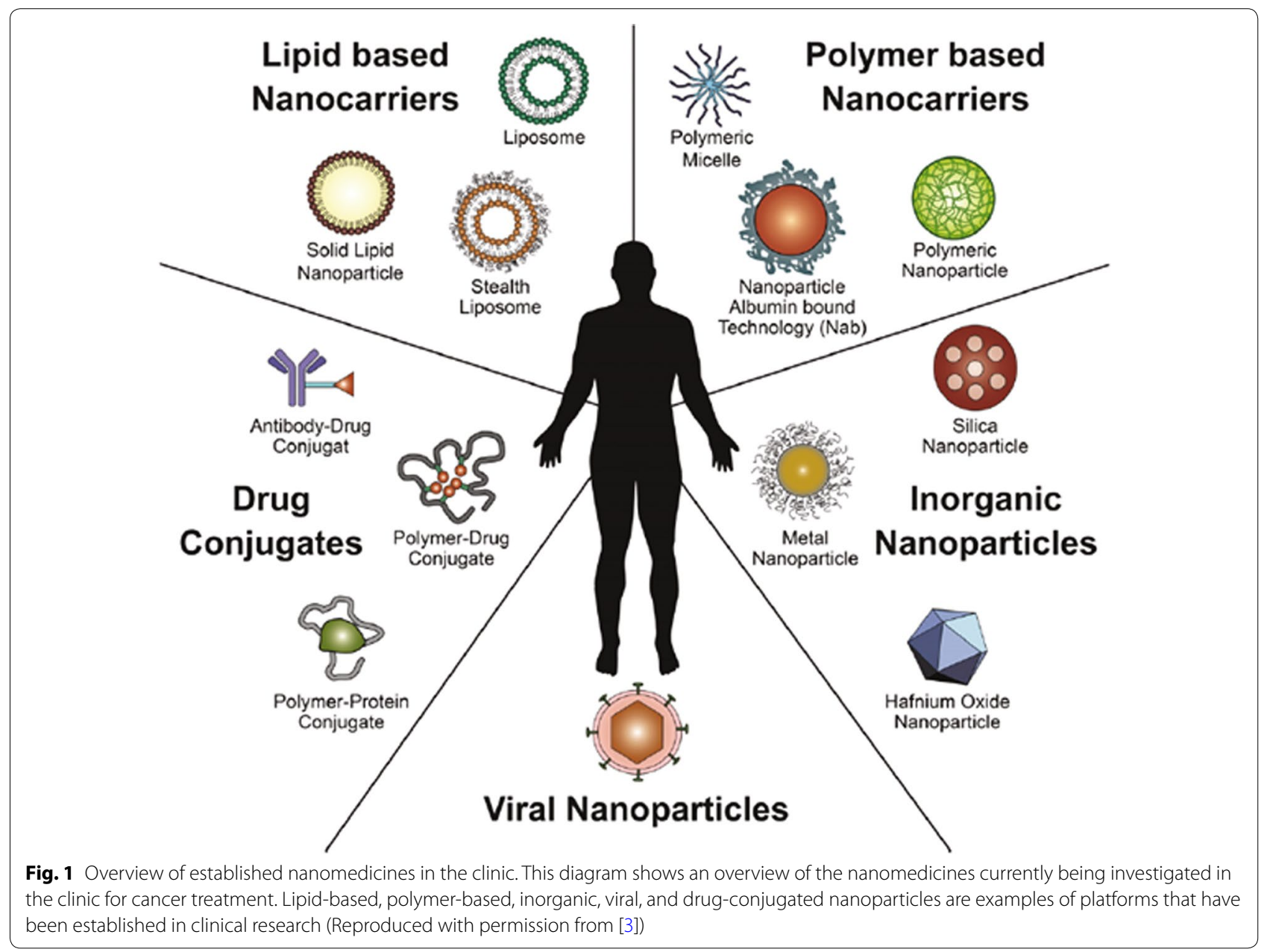


Table 1 Currently approved nanomedicines in the clinic

\begin{tabular}{|c|c|c|c|c|c|}
\hline Year approved & Name & Type & Active drug & Diameter (references) & Type of cancer \\
\hline Japan (1994) & Zinostatin stimalamer & $\begin{array}{l}\text { Polymer protein con- } \\
\text { jugate }\end{array}$ & $\begin{array}{l}\text { Styrene maleic anhy- } \\
\text { dride neocarzinostatin } \\
\text { (SMANCS) }\end{array}$ & * & Renal cancer \\
\hline $\begin{array}{l}\text { FDA (1995) } \\
\text { EMA (1996) }\end{array}$ & Doxil/caelyx & Liposome (PEGylated) & Doxorubicin & $80-90$ nm [82] & $\begin{array}{l}\text { HIV-associated Kaposi's } \\
\text { sarcoma, ovarian cancer, } \\
\text { metastatic breast cancer, } \\
\text { multiple myeloma }\end{array}$ \\
\hline FDA (1996) & DaunoXome & $\begin{array}{l}\text { Liposome (non- } \\
\text { PEGylated) }\end{array}$ & Daunorubicin & 45 nm [83] & $\begin{array}{l}\text { HIV-associated Kaposi's } \\
\text { sarcoma }\end{array}$ \\
\hline Taiwan (1998) & Lipo-Dox & Liposome & Doxorubicin & 180 nm [84] & $\begin{array}{l}\text { Kaposi's sarcoma, breast } \\
\text { and ovarian cancer }\end{array}$ \\
\hline FDA (1999) & DepoCyt & Liposome & $\begin{array}{l}\text { Cytosine arabinoside } \\
\text { (cytarabine) }\end{array}$ & $10-20 \mu \mathrm{m}[84]$ & Neoplastic meningitis \\
\hline EMA (2000) & Myocet & Liposome & Doxorubicin & $190 \mathrm{~nm}[84]$ & Breast cancer \\
\hline $\begin{array}{l}\text { FDA (2005) } \\
\text { EMA (2008) }\end{array}$ & Abraxane & $\begin{array}{l}\text { Nanoparticle albumin } \\
\text { bound }\end{array}$ & Paclitaxel & 130 nm [27] & $\begin{array}{l}\text { Advanced non-small-cell } \\
\text { lung cancer, metastatic } \\
\text { pancreatic cancer, meta- } \\
\text { static breast cancer }\end{array}$ \\
\hline FDA (2006) & Oncaspar & PEG protein conjugate & L-Asparaginase & 50-200 nm [84] & Leukemia \\
\hline South Korea (2007) & Genexol-PM & $\begin{array}{l}\text { PEG-PLA polymeric } \\
\text { micelle }\end{array}$ & Paclitaxel & 20-50 nm [85] & $\begin{array}{l}\text { Breast cancer, Lung cancer, } \\
\text { Ovarian cancer [126] }\end{array}$ \\
\hline EMA (2009) & MEPACT & $\begin{array}{l}\text { Liposome (non- } \\
\text { PEGylated) }\end{array}$ & Mifamurtide & * & Osteosarcoma \\
\hline EMA (2010) & NanoTherm & Iron oxide nanoparticle & - & 20 nm [86] & $\begin{array}{l}\text { Thermal ablation glioblas- } \\
\text { toma }\end{array}$ \\
\hline FDA (2012) & Marqibo & $\begin{array}{l}\text { Liposome (non- } \\
\text { PEGylated) }\end{array}$ & Vincristine & 100 nm [87] & $\begin{array}{l}\text { Philadelphia chromosome } \\
\text { negative acute lympho- } \\
\text { blastic leukemia }\end{array}$ \\
\hline FDA (2015) & MM-398 (Onivyde) & Liposome (PEGylated) & Irinotecan & 80-140 nm [88] & $\begin{array}{l}\text { Metastatic pancreatic } \\
\text { cancer ( } 2 \text { nd line) }\end{array}$ \\
\hline
\end{tabular}

* Data could not be found

This review will discuss the current use of clinically approved nanomedicines, the investigation of nanomedicines in clinical trials, and the challenges that may hinder development of the nanomedicines for cancer treatment. Several properties of nanocarriers make them suitable for delivering chemotherapeutic drugs to the target tumor tissue. Small molecule drugs like most chemotherapies have very short circulation half lives inside the body and nanoparticles can be made long-circulating thereby improving the bioavailability of these drugs and thus improving efficacy without the need for higher doses [4-6]. Nanoparticles also offer the opportunity to control the release of the encapsulated payload such that a high percentage of the trapped drug is released after the particles have reached their target tissue. This property of controlled release from nanoparticles can improve efficacy of the drugs while reducing off-target toxic effects [4-6]. Several of these virtues of nanoparticle-based drug delivery are discussed next.

\section{Nanocarrier properties Physico-chemical properties}

The nanomaterials available for cancer research can be modified in size, shape, and surface characteristics for customization to treat specific tumors. Size is important for travel through the bloodstream and subsequent delivery of the nanocarriers to tumor tissue. While smaller nanoparticles can accumulate more easily in the leaky blood vessels of tumors than those that are larger, they can also extravasate into normal tissue. On the other hand, larger nanoparticles cannot extravasate as easily and thus their distribution in the bloodstream is highly variable [6]. The optimization of nanoparticle size may help improve specific uptake into tumor tissue. The shape of the nanocarriers may impact fluid dynamics and thus influence uptake. Currently, the use of spherical nanocarriers appears to be more common than that of the nonspherical variety due to challenges in synthesis and testing [7]. 
The charge of nanocarriers may also affect their stability and distribution in the blood. Positively charged nanoparticles were previously shown to most effectively target tumor vessels, but a switch to a neutral charge after extravasation allowed quicker diffusion of the nanoparticles to the tumor tissue [8]. The surface of the nanocarriers can also be modified with ligands that may prolong blood circulation and promote specific types of endocytosis and cellular uptake into tumor tissue.

\section{Solubility, degradation, and clearance}

Drugs with poor water solubility may be eliminated from the bloodstream before reaching tumor tissue. The use of hydrophilic nanoparticles to encapsulate these drugs may improve their solubility, in turn improving their bioavailability in vivo and thus allow more effective delivery [3]. Coating nanoparticles with polyethylene glycol (PEG), a hydrophilic and non-ionic polymer, was shown to increase solubility and stability of nanoparticles [6]. Since PEG is uncharged, it does not disrupt the function of charged molecules, such as DNA [9].

The reticulo-endothelial system (RES) recognizes hydrophobic materials as foreign and eliminates them from the bloodstream, taking them up in the liver or the spleen. Foreign materials coated with opsonin proteins are more easily recognized by monocytes and macrophages [10]. Opsonization of hydrophobic molecules can reduce their ability to reach the tumor tissue and trigger inflammation following the secretion of cytokines from the phagocytic cells $[10,11]$. PEGylated nanoparticles mask their hydrophobicity and therefore can prolong their circulation in the blood to allow adequate time to reach tumor tissue [9]. This reduction in clearance not only increases the half-life of the nanoparticle but also improves its bioavailability $[9,10]$. This improvement in bioavailability allows the drug to circulate in the blood for a longer period of time, preventing degradation before reaching the tissue of interest. Additional modifications to the nanoparticle surface, such as ligands to overexpressed receptors, may assist in specific uptake of the drugs in the tumor. Controlled release mechanisms may also prevent non-specific delivery of the toxic drug to normal tissue.

\section{Targeting}

Nanocarriers may be modified to utilize passive and active targeting mechanisms to reach tumor tissue (Fig. 2). The enhanced permeability and retention (EPR) effect allows nanoparticles to passively accumulate in the leaky blood vasculature exhibited by tumors without any surface modifications $[3,5,6]$. Passive targeting, however, cannot eliminate the potential of nanocarriers building up in tissues that normally have fenestrated blood vessels, such as the liver or the spleen [3]. Furthermore, the microenvironments of specific tumors vary and may pose as barriers for nanomedicine development.

Active targeting utilizes the attachment of ligands to surface of the nanocarriers [12]. These ligands have high specificity to receptors and other cancer-specific targets that are overexpressed on the surface of tumor cells, such as glycans [12]. Conjugation of these ligands may eliminate non-specific uptake of nanocarriers to tissue other than tumor tissue. Such ligands may include transferrin, folic acid, enzymes, engineered antibodies, and macromolecules like proteins and carbohydrates [3, 6]. The density of these ligands should be optimized to allow nanoparticles to avoid recognition by the RES and interaction with serum proteins, thus prolonging their blood circulation time [3].

\section{Stimuli-responsive and triggered release systems}

The use of stimuli-responsive systems may reduce nonspecific exposure to chemotherapeutic drugs (Fig. 2). Both internal and external stimuli can trigger the release a Passive Targeting

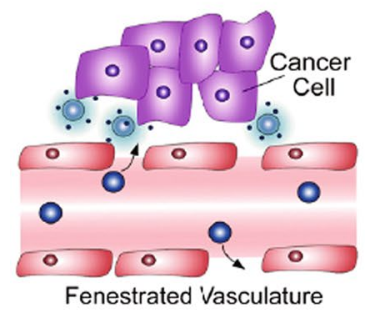

b Active Targeting

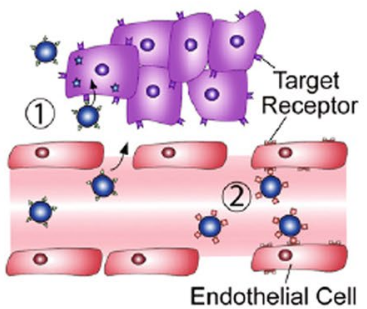

c Triggered Release

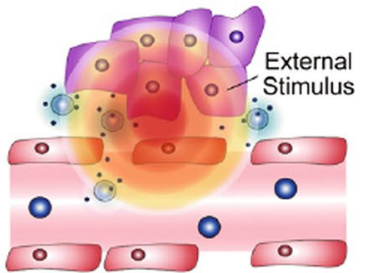

Fig. 2 Types of targeting for nanoparticle delivery to tumor tissue. a Passive targeting relies on the leaky vasculature that is exhibited by tumors, allowing nanoparticles to travel through the fenestrations and reach tumors. b Active targeting can be used when nanoparticles have ligands on their surface that can recognize and bind receptors that are overexpressed on tumor cells. c Triggered release allows nanoparticles to congregate if exposed to an external stimulus such as a magnetic field or light (Reproduced with permission from [3]) 
of drugs by evoking a change in the nanocarriers. Changes in $\mathrm{pH}$, redox, ionic strength, and stress in target tissues are examples of internal stimuli [3]. The differences in the $\mathrm{pH}$ of blood and intracellular organelles may allow nanocarriers to release drugs specifically when they reach tumor tissue [13]. $\mathrm{pH}$ responsive sodium alginate and hydroxyapatite bi-coated iron oxide nanoparticles were shown to exhibit a controlled drug release profile for the hydrophobic drugs curcumin and 6-gingerol and may offer a potential platform for cancer therapy [12]. Tumors typically have a hypoxic microenvironment with low oxygen and nutrient levels and thus high levels of reductive agents, such as glutathione [13-15]. Nanocarriers with disulfide bonds may be used to target these types of tissue. Nanocarriers with disulfide bonds can help carry out the redox reaction that oxidizes glutathione, which may increase cellular apoptosis [14].

External (physical) stimuli include temperature, light, ultrasound, magnetic force, and electric fields [3]. Hyperthermia, a temperature change with a range between 37 and $42{ }^{\circ} \mathrm{C}$, may increase the permeability of blood vessels and enhance the delivery of nanocarriers, such as ThermoDox, which are responsive to these changes [16]. Use of near-infrared wavelengths may increase penetration into the body, compared to UV light, which is absorbed superficially by the skin, blood, and tissues less than $10 \mathrm{~cm}$ in depth [17]. Ultrasound systems may help diagnose cancers by triggering the release of contrast agents [18]. Magnetic and electric fields may allow nanoparticles to aggregate to specific sites [19].

The use of verteporfin (BPD) in nanoparticles is an example of nanoparticles that use a light triggered external stimulus. By itself, BPD is biocompatible. However, when exposed to infrared light, BPD produces reactive oxygen species (ROS) that can damage DNA, resulting in cell death. In a study by Konan-Kouakou et al., BPD loaded Poly(D,L-lactide-co-glycolide) (PLGA) nanoparticles were injected into mice with rhabdomyosarcoma (M1) tumors [20]. The mice were then exposed to laser light at $50 \mathrm{~J} / \mathrm{cm}^{2}$ at $690 \mathrm{~nm}$ following a time delay (15, 30 , and $60 \mathrm{~min}$ post injection) and evaluated for tumor growth for 20 days. After 20 days, the mice with shorter time delays (15 and $30 \mathrm{~min}$ ) had more tumor-free mice (66 and 75\% respectively) than those with the $60 \mathrm{~min}$ time delay (33\%). These results were due to the rapid nanoparticle clearance in the blood stream. Another result of this rapid clearance was the reduction of side effects. The only side effect noted was photosensitivity of the skin. The $15 \mathrm{~min}$ mice had, at worst, visible pink erythema and a few broken blood vessels in some individuals, and these symptoms went away after 3 days. The $60 \mathrm{~min}$ mice had no side effects due to the rapid clearance on the nanoparticles.

\section{Combination therapy and theranostics}

The ability of nanomedicines to carry multiple therapeutic agents may increase their ability to improve treatment. Co-loaded nanoparticles with bortezomib and doxorubicin were found to exhibit an antitumor synergistic effect on ovarian cancer [21]. Loading multiple siRNAs alone or together with other drugs may increase sensitivity of the tumor to the treatment $[22,23]$. The use of stimuli-responsive systems with targeting ligands has also been investigated. An emerging method is the use of theranostics, which combines both the ability to diagnose and treat cancers. In theranostics, not only can drug release be monitored, but the effects of the drugs in the tumor tissue can also be visualized [24]. These abilities may open their potential to be used for personalized treatment [25].

Successful delivery of chemotherapeutic drugs is often dependent on the properties of the biological barriers involved (Fig. 3) in cancer. Next, we will discuss multiple biological barriers to effective drug delivery.

\section{Biological barriers to effective drug delivery Reticuloendothelial system}

The reticuloendothelial system (RES), also known as the mononuclear phagocyte system (MPS), consists of both cellular and noncellular components. Phagocytic cells may bind nanoparticles and cause a release of cytokines, increasing nanoparticle clearance from the bloodstream and local inflammation of tissue [11]. Proteins, lipids, and other macromolecules may also bind to the surface of the nanoparticles and create a "biomolecular corona" around the nanoparticles. This effect may increase clearance from the bloodstream via recognition by the immune system or disrupt the ability of the nanoparticles to be internalized by the tissue of interest $[26,27]$. Surface modifications of nanoparticles may permit escape from the RES and prolong their circulation time in the bloodstream, while preventing damage of normal tissue. Such modifications may involve zwitterionic ligands such as cysteine and glutathione or PEGylation $[11,26]$. PEGylated nanoparticles can avoid recognition by RES, thus extending the time available for them to travel through the blood and reach target tumor tissue $[9,11]$.

Coating the nanoparticles with membranes derived from leukocytes or erythrocytes may enhance their selfrecognition [11]. Use of ligands such as CD47-SIRP $\alpha$ to create signals may inhibit phagocytic clearance [28]. Spherical nanoparticles may congregate in the center of blood vessels and thus be less likely to extravasate via interactions with endothelial cells [29]. Use of disc-like nanoparticles may increase endothelial cell interactions and thus enhance their ability to extravasate into tumor tissues [30, 31]. Toxicity of the nanoparticles to organ 


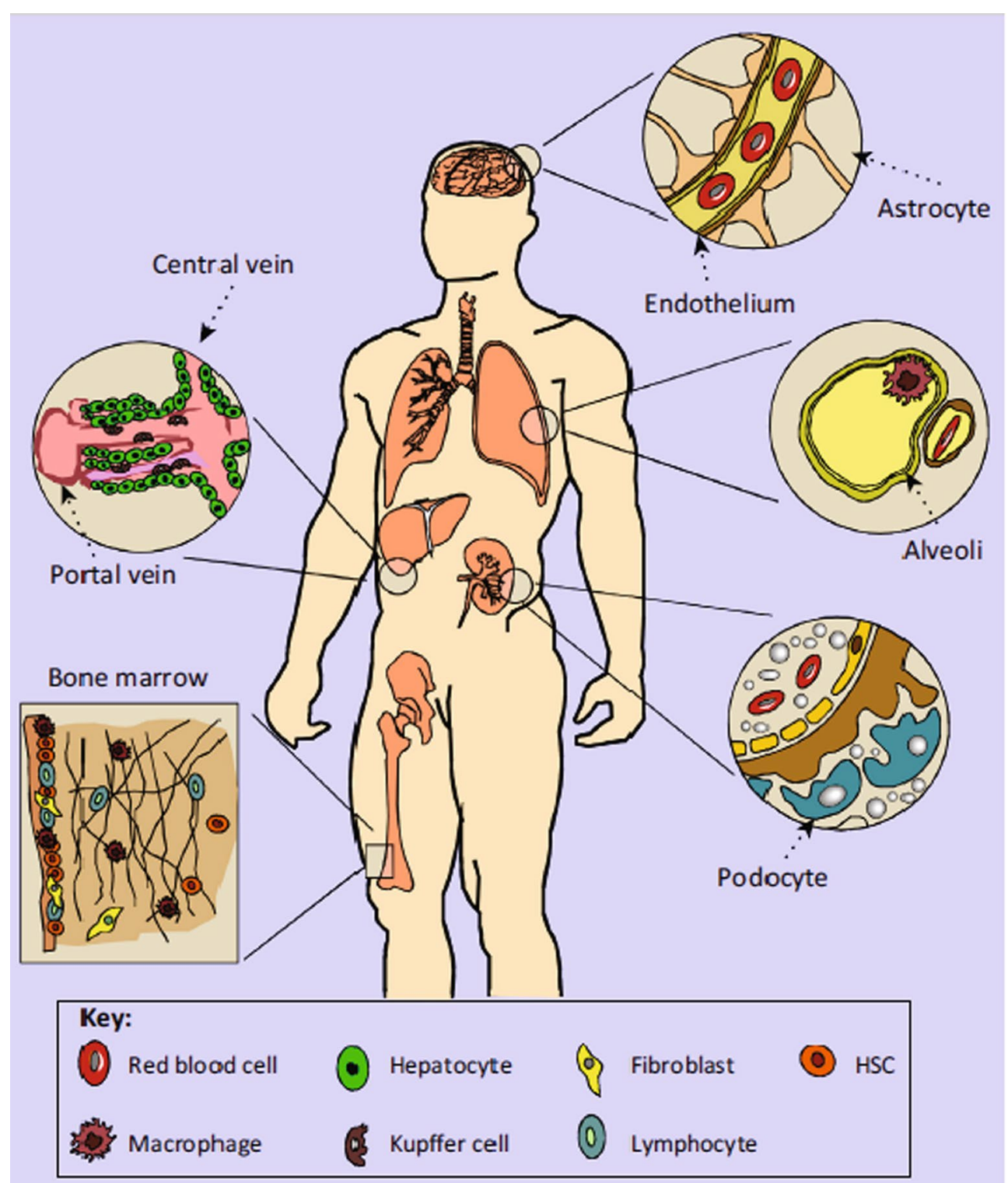

Fig. 3 Organ systems that affect nanoparticle delivery. The method of entry affects circulation time, organ processing, and overall efficacy. Intravenously injected nanoparticles can extravasate from the bloodstream and enter organs such as the liver, spleen, bone marrow, and central nervous system. Nanomedicines that are administered orally can enter the gut and pass through the liver via the hepatic portal system. Inhaled nanomedicines may contact macrophages in pulmonary alveoli. Following circulation in organs, nanoparticles may encounter renal clearance in the kidneys (Reproduced with permission from [11])

systems of the RES should also be considered when designing their construct.

\section{Renal system}

The kidney is responsible for filtering circulating blood, and therefore the barriers involved in kidney filtration need to be considered when designing nanoparticles. After passing through the fenestrated endothelium with $70-100 \mathrm{~nm}$ pores, nanoparticles must pass through the glomerular basement membrane, a thick layer of extracellular matrix that sits between the capillary endothelium and podocytes that permit clearance for $2-8 \mathrm{~nm}$ particles [11]. Openings of slit diaphragms that lie between epithelial podocyte extensions are regulated by proteins such as nephrin and CD2-associated protein, which generally allow the passage of water and small molecules [32].

Size, charge, and shape are all characteristics that affect the clearance of nanoparticles in kidneys. Spherical 
nanoparticles with diameters less than $6 \mathrm{~nm}$ were shown to have greater renal clearance than those with diameters greater than $8 \mathrm{~nm}$ [12]. The glomerular basement membrane is negatively charged, and therefore cationic nanoparticles of 6-8 $\mathrm{nm}$ exhibit greater clearance than those negatively charged or neutral of the same size [33]. Single-walled carbon nanotubes (100-500 $\mathrm{nm}$ length and $0.8-1.2 \mathrm{~nm}$ diameter) were found to pass through the fenestrated capillary endothelium by their long axis, despite their large molecular mass [34].

Although reducing nanoparticle size may enhance renal clearance, efficacy may be compromised. Multistage, biodegradable nanoparticles that dissolve into smaller particles that can be cleared by the kidney may be effective [35]. However, this effect may also pose a risk of nonspecific degradation, in which nanoparticles release drugs and other agents prior to arriving at target tumor tissue. Levels of the nano-encapsulated drugs must be sustained in the plasma for a chemotherapeutic effect, as well as eliminated from the bloodstream safely to limit potential long-term adverse effects. Personalized considerations must also be made for patients with renal deficiencies [11].

\section{Blood-brain barrier}

The blood-brain barrier (BBB) poses a challenge for treating brain cancers, since it only permits passage of less than $2 \%$ of molecules, including ions, nutrients, specific peptides and proteins, and leukocytes [36]. The barrier consists of endothelial cells joined by tight junctions and enclosed by astrocytic cells, basal lamina, pericytes, and microglia. Current methods for increasing penetration may involve direct introductions into the brain such as intraventricular or intracerebral injection, infusion, and implantation and may increase toxicity risks and non-uniform drug dispersals [11].

Receptor-mediated endocytosis may be responsible for nanoparticle entry through the blood brain barrier [37]. This method relies on the conjugation of ligands or peptides to receptors that bind nanoparticles to the surface of the endothelial cells [11]. Surfactants such as poloxamer 188 or polysorbate 80 may be used to coat nanoparticles to increase adsorption of serum proteins such as apolipoproteins $\mathrm{E}$ or $\mathrm{A}-\mathrm{I}$ and thus enhance penetration through the BBB [38]. Covalent attachment of apolipoproteins to human serum albumin-coated nanoparticles may also improve their ability to cross the BBB [39]. Use of targeting ligands that bind to receptors on endothelial cells, such as transferrin, lactoferrin, and low-density lipoprotein receptors, may also promote BBB penetration [37, 40, 41].

Nanoparticle size and charge are essential considerations for passing through the blood brain barrier. One study demonstrated that nanoparticles with diameters of 20-70 nm are preferential for transport [42]. Neutral and anionic nanoparticles were found to result in less neurotoxicity than cationic nanoparticles for an in situ perfusion study of rat brains [43].

Although reaching the brain may be a challenge for nanotherapy targeted for brain cancers, nanomedicines can also unnecessarily accumulate in the brain and cause toxic short-term and long-term effects. Nanoparticles containing metals such as copper, silver, and aluminum may degrade the BBB and cause neurotoxicity [44]. Microglial cells coordinate inflammatory signals and responses in the brain, and they can be activated by nanoparticle proximity and uptake, resulting in increased levels of inflammation [45]. Designing therapies that reduce activation of microglial cells may be useful in reducing neurotoxic effects [11].

\section{Pathophysiological barriers in cancer}

Tumor tissue is often characterized by leaky vasculature rich in fenestrations and poor in pericyte coverage. This phenomenon, known as the enhanced permeability and retention (EPR) effect, has been utilized for passive targeting of nanoparticles to tumor tissue, but deeper penetration into the tumor is frequently restricted due to heterogeneity of the tumor microenvironment [46]. Composition and structure of extracellular matrix, along with tumor vasculature, is highly variable and dependent on cancer type, location, and progression state, along with patient-specific characteristics [11].

Methods to increase nanoparticle penetration into the tumor bed are currently being investigated. Use of smaller nanoparticles may allow enhanced passage through the vasculature and deeper penetration into the tumor [47]. Multistage nanoparticles break down into their smaller components, and their use may extend circulatory half-life, while allowing enhanced penetration [35]. Nanoparticles with the ability to respond to environmental cues, termed "smart," may also improve bioavailability and be an avenue for personalized treatment [48].

A wide variety of materials can be used to create nanoparticles for drug delivery. The most common materials include proteins, liposomes, polymers, polymer-lipid hybrids, dendrimers, hydrogels, phase change materials, and inorganic materials.

\section{Types of nanoparticles}

\section{Protein-drug conjugated nanoparticles}

Protein-drug conjugated nanoparticles consist of proteins directly conjugated to drug molecules. The link between the protein and the drug is typically biodegradable upon arrival in the cell. This can lead to premature 
release of the drug, as the biodegradable linker is readily destroyed by proteases and redox-altering agents found in blood. Recent platforms, such as protein-drug conjugated systems with linkers that stay in place until the nanoparticles reach the target site, have overcome this barrier. This system allows more precise and controllable delivery of the cytotoxic drug molecules, lessening the toxic effects of the treatment on the body [49]. Proteindrug conjugated nanoparticles are typically very small $(10 \mathrm{~nm})$, allowing the nanoparticle to have a long halflife in vivo and thus facilitating its delivery to the target tumor site [50]. More recently, antibody proteins have been added to protein-drug conjugated nanoparticles, improving their targeting ability. An inherent issue with protein-based nanoparticles is that the structural sensitivity of some drugs makes them difficult to attach to a protein base. Therefore, certain drugs may not be suitable for this nanoparticle delivery system. The linkers used in these systems may also be rapidly degraded by enzymes and agents commonly found in blood plasma, leading to premature activation of the drug and a decrease in circulation time, while increasing the drugs bioavailability [51].

\section{Liposomal nanoparticles}

Liposome-based nanoparticles are spherical nanoparticles created via the use of lipid bilayers. These nanoparticles are created immediately when an amphiphilic lipid is added to water or other hydrophilic liquids, yielding spheres roughly between 50 and $500 \mathrm{~nm}$. This procedure allows for the encapsulation of hydrophilic drug molecules by simply dissolving the drug in the liquid used for formation of the nanoparticles. Hydrophobic and amphiphilic drugs can be encapsulated by direct addition to the lipid solution before formation of the nanoparticles, leading to a layer of drug molecules between the lipid bilayer [49]. Common lab methods used to create liposomal nanoparticles include sonication, extrusion, reversephase evaporation, and solvent injection [52].

Thermosensitive liposomes may allow the release of encapsulated drugs at specific temperatures [53]. Use of these liposomes allows for targeted drug delivery to areas where energy sources, such as high-intensity ultrasound, microwaves, and radio frequencies, are applied. The use of high-frequency ultrasound, for example, has successfully been used in clinical applications of liposomes to enhance drug delivery [54].

Hydrophilic drug molecules do not easily diffuse through the lipid bilayer, while hydrophobic and amphiphilic drugs easily diffuse through the lipid bilayer, potentially leading to toxicity in normal tissues. Use of liposomes may alleviate the issue of hydrophilic drug delivery. Since the lipid bilayer is similar in structure to the cell membrane, the liposomal nanoparticle can either fuse with the cell membrane or lyse once combined with harsh environments inside the cell (i.e. inside peroxisomes and lysosomes), releasing the drug inside of the cell. Hydrophobic and amphiphilic drug molecules can be kept inside of the liposomal nanoparticle via the creation of a polymeric encasement around the lipid bilayer. Depending on the polymer used, the ability of the nanoparticle to easily fuse with the target cell can be hindered, and in such cases, an additional mechanism must be incorporated to release the drug payload. The use of polymeric coatings can also lead to other key benefits, such as increasing circulation time, improving bioavailability of encapsulated drug, increasing targeting efficiency, and altering surface charge of the liposomes [49].

\section{Polymeric nanoparticles}

Polymeric nanoparticles are comprised of synthetic polymers, allowing customization of many key properties, such as molecular weight, biodegradability, and hydrophobicity. The synthesis of polymeric nanoparticles has also been well studied. A variety of methods have been designed to efficiently encapsulate drug molecules. Some examples of these methods include nanoprecipitation, electrospray, and emulsification. Polymeric nanoparticles are typically comprised of dense matrices with wellknown degradation curves, making the drug release of these nanoparticles easier to manipulate in comparison to many other nanoparticle drug delivery systems [49].

Issues with using polymeric nanoparticles include limited shape and wide size distribution. Polymeric nanoparticles are typically spherical, while a wide variety of different sizes may be generated during synthesis. New techniques are currently being investigated to resolve these issues. The most recent approach is particle replication in nonwetting templates (PRINT). PRINT allows for the creation of uniform polymeric nanoparticles, allowing the customization of properties such as shape and size. This, the aesthetic properties of the nanoparticles, as well as the amount, rate, and pathway used for cellular uptake of the encapsulated drug molecule, may be tailored [55].

\section{Dendrimeric nanoparticles}

Dendrimeric nanoparticles are comprised of dendrimers, which are spherical macromolecules with many branches originating from a central point. These nanoparticles are created layer by layer. The initial core of the dendrimer is incorporated onto the previous layer before branches are allowed to form. By using specific initiator cores, the size and degree of branching of the dendrimer can be easily manipulated, allowing for the polydispersity of the nanoparticle to be minimized. By carefully planning 
the scheme of cores and branching units, the molecular weight, size, branch density, flexibility, and water solubility can be specified [49].

\section{Hydrogels}

Hydrogels are three-dimensional networks of crosslinked water soluble polymers that are able to retain fluid in large quantities. Most synthetic hydrogels are not biodegradable, but enzymatic, hydrolytic, and stimuliresponsive components can be added into the hydrogel matrix in order to create nanoparticles that are degradable under certain conditions. The uniqueness of hydrogels is in their fluid retainment-the high water content is very similar to biological tissues, reducing tension when introduced to tissue and making this nanoparticle biocompatible [56]. By controlling the amount of cross linking in the hydrogel matrix, the porosity of the hydrogel can be adjusted to control drug loading and release rates. Hydrogels also naturally have a positive surface charge and thus may strongly interact with the negatively charged cell membranes, increasing cellular uptake of drug payload. Since serum proteins also are negatively charged, however, hydrogels may aggregate to serum proteins, decreasing the circulation time of the nanoparticles [49].

\section{Other nanoparticle platforms}

One well-characterized example of inorganic, metallic nanoparticles is gold. Gold has been widely used for both detection and direct cancer therapy with and without drug loading. The strong optical absorbance of gold allows it to be used for detection, while its photothermal properties make it suitable as an anticancer therapy. Complex structures with gold may be designed to increase the efficiency of the drug release. For example, drug molecules may be conjugated to the surfaces of the gold nanoparticles, while structures with hollow interiors may also be created to increase encapsulation efficiency. Many of these structures can be easily created and specifically designed, such as to include a wide range of optical properties. Controlled drug release is possible by adding a layer of thermoresponsive polymers on the nanoparticle surface. These polymers shrink in heat and expand in cooler temperatures, allowing for the control of the diffusion rate of the loaded drug particles. This technology can be combined with the photothermal properties of gold for novel drug delivery to specific regions. Shining a laser, for example, on the tumors to heat the gold nanoparticles when they are near the tumor site can increase effective drug loading while minimizing nonspecific toxicity [49].

Carbon nanotubes have also been analyzed for cancer treatment. These structures can bind to various biological materials and enter cells via endocytosis. Single walled carbon nanotubes (SWCNTs) form highly stable suspensions in physiological buffers, making them suitable for use in biological environments. These SWCNTs also bind to attached molecules via cleavable disulfide bonds, allowing for drug materials to be removed from the SWCNTs in the presence of certain enzymes [57]. Carbon nanotubes have also shown promise in potential treatments with their interesting optical properties. Like gold, carbon nanotubes can be used to photochemically damage tumor cells via photothermal and photodynamic therapy [58]. Carbon nanotubes can also be used to image cancer growth via resonance-enhanced Raman signatures $[49,59]$.

A third type of nanoparticle with cancer treatment potential are silver nanoparticles. While the exact mechanism of action of silver nanoparticles in cancer remains unclear, silver reacts with the acidic environment that is often found in cancer cells to create reactive oxygen species. These reactive oxygen species can induce damage to cellular materials and apoptosis occurs. Silver has also been observed to inhibit vascular endothelial growth factor (VEGF), and thus possesses anti-angiogenic effects on cancer cells. In a study performed by Almajhdi et al., it was shown that the addition of silver nanoparticles to a nanofiber had an antitumor effect in vitro, with fibers containing $1 \%$ silver causing $8.8 \%$ of cancer cell death and an increase to $7 \%$ silver resulted in $67.6 \%$ cancer cell death. It was also seen that these nanofibers were able to create an inhibition zone of up to $10 \mathrm{~mm}$ (diameter) devoid of several bacterial strains [60], an advantage against infections if such a nanofiber was inserted into a tumor site. The main concern with the use of silver is toxicity, which can be overcome by creating nanoparticles with silver cores and a biocompatible shell. The outer layer of the nanoparticle is designed to break down in specific environments. Drug molecules can also be conjugated to this outer layer [61]. Evidence of the anricancer efficacy of silver nanoparticles in vivo using animal models of cancer is insufficient and warrants further studies.

Although there are multiple types of nanoparticles that can be created for cancer treatment, many of the treatments currently undergoing clinical trials are of the same nanoplatforms - mainly liposomal and to a lesser extent polymeric nanoparticles. This can be seen in Table 2, which shows several nanoparticle treatments that are in clinical trials in the United States. In order to further discuss clinical cancer nanomedicine, the approval of MM-398, a liposomal nanomedicine created to treat metastatic pancreatic cancer, is discussed. The drug's preclinical and phase I, II, and III trials are reviewed in a case study format. 


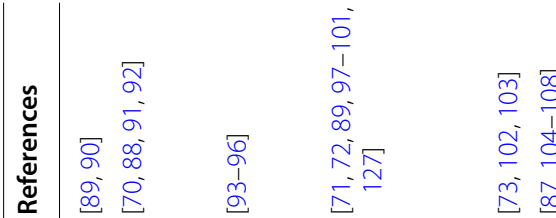

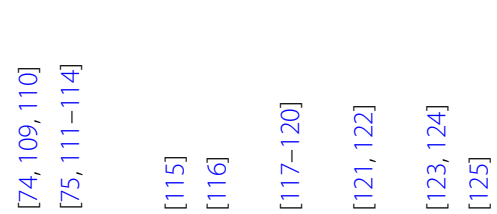

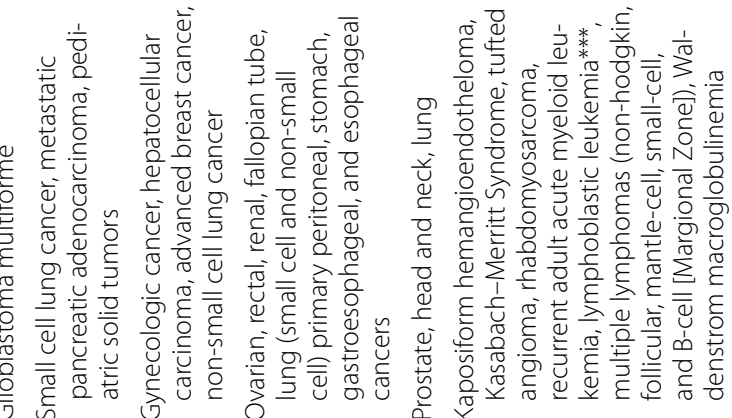

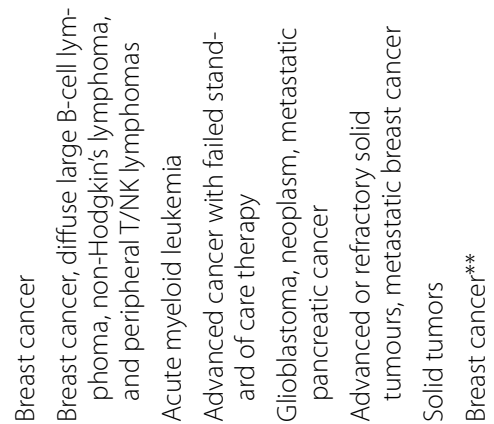

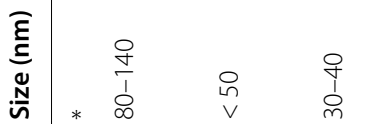

$\stackrel{8}{\circ}$

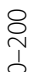

$8 * * * * \frac{8}{i} \frac{\stackrel{m}{l}}{8}$

产

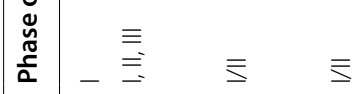

$-\Sigma$

$==\quad-\equiv \equiv \equiv-$

o.

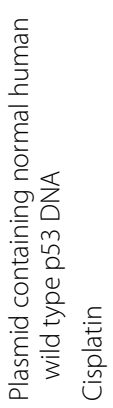

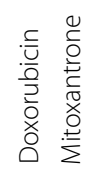

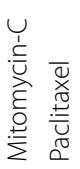

竞

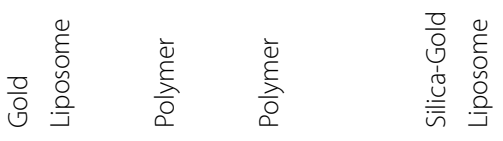
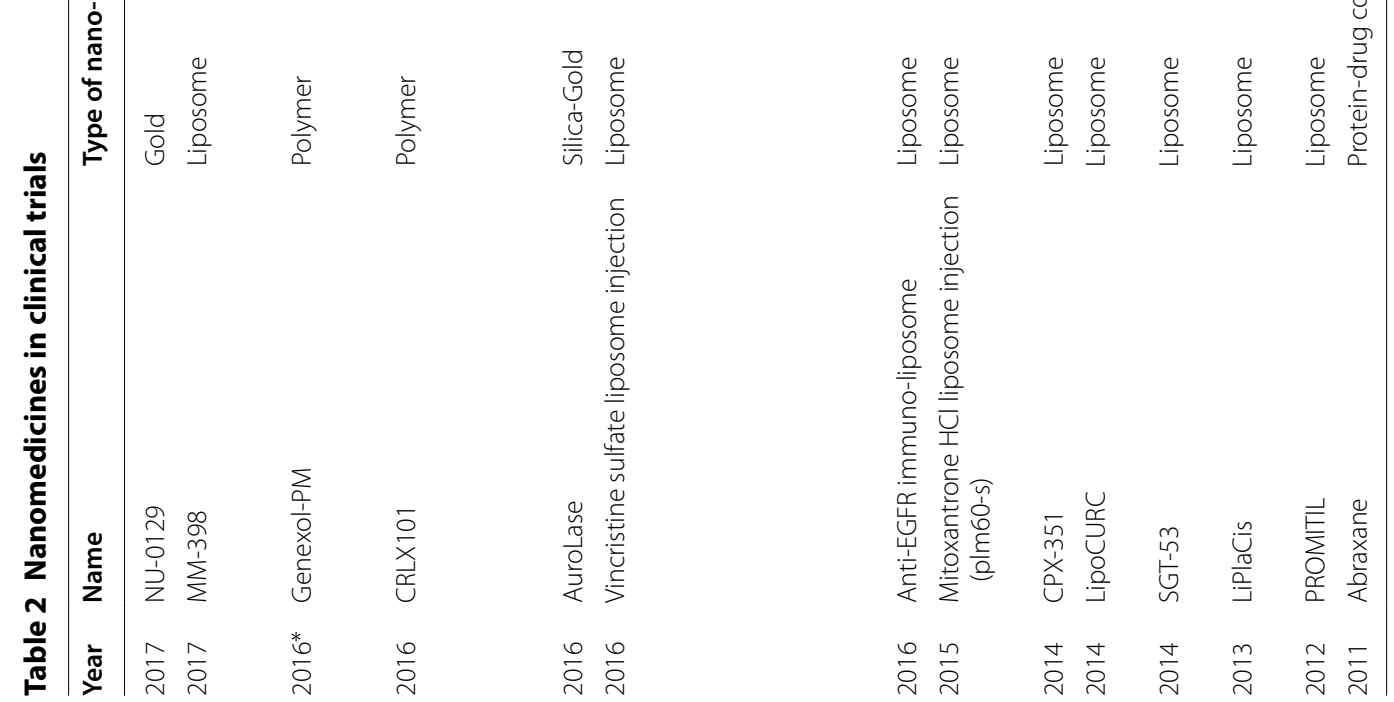

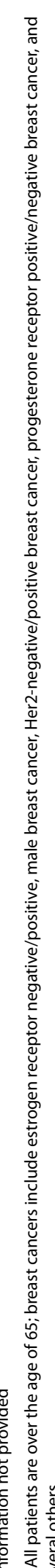




\section{Case study: MM-398 clinical trials}

First approved in 1996, irinotecan (formerly known as CPT-11) is a semisynthetic analog of the cytotoxic alkaloid camptothecin. It is isolated from Camptotheca acuminata (family Nyssaceae), a tree indigenous to China. Camptothecin is known to have strong antitumor properties, and its analog irinotecan is typically used to combat colon and pancreatic cancers. Irinotecan is thought to have cytotoxic effects on cells in S phase, inserting itself into the DNA replication fork and effectively halting mammalian DNA topoisomerase I in its place, as seen in Fig. 4. This effect blocks DNA replication, inhibiting nucleic acid synthesis and inducing the DNA strands to break apart, ultimately causing cell death in proliferating cells $[62,63]$. The active metabolite of irinotecan, SN-38, is in constant equilibrium with irinotecan (Fig. 5). Both substances have a pH-dependent equilibrium between their active lactone and inactive carboxylate forms. Although irinotecan and SN-38 both

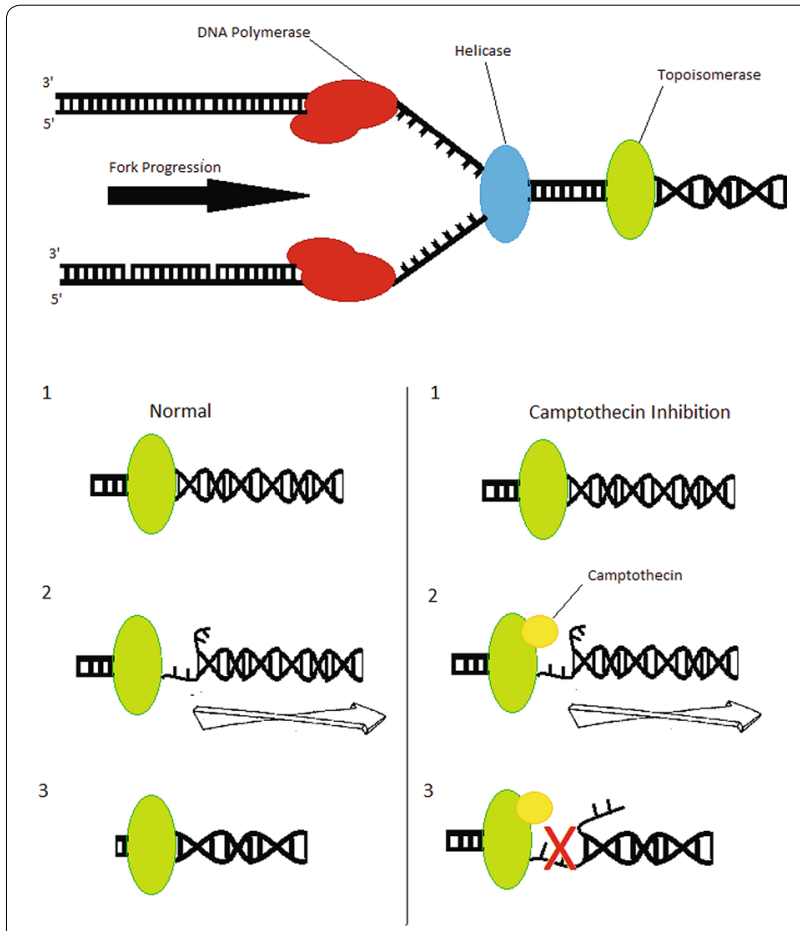

Fig. 4 A schematic illustrating replication fork arrest by a drugaborted topoisomerase I-DNA cleavable complex. In this model, the camptothecin trapped topoisomerase I-DNA cleavable complex is viewed as a bulky DNA lesion which arrests the replication fork by blocking the movement of replication machinery. This blockage also alters the physical state of the cleavable complex and possibly leads to fork breakage at the complex site. At low levels of cleavable complexes, when only one replication fork is arrested, continued replication by the other unimpeded fork on the same plasmid DNA leads to the formation of linearized replication products. The irreversible replication arrest and fork breakage may be the cause of camptothecin's S-phase-specific cytotoxicity [62, 63]

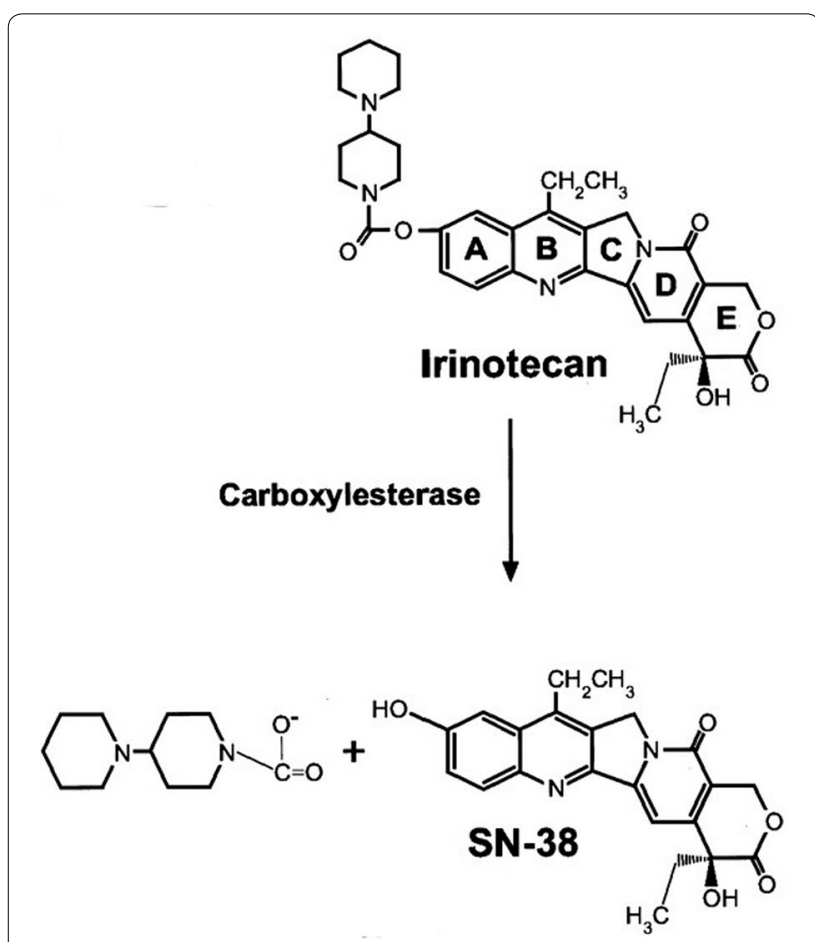

Fig. 5 Metabolic pathway of irinotecan activation into SN-38 (Reproduced with permission from [81])

have the same DNA damaging ability, $\mathrm{SN}-38$ is known to be roughly 100-1000 times more potent than irinotecan. Using unencapsulated irinotecan can thus lead to issues in toxicity and efficacy. Containing the irinotecan drug particles in liposomes may be a solution. Separation of the drug molecules from the inside of the body results in a lower plasma concentration $\left(\mathrm{C}_{\max }\right)$ and lower circulation time of the drug, both of these leading to a lower toxicity. A higher concentration of the drug is able to accumulate in the tumor tissues, possibly due to large and leaky vasculature in the tumor tissue [64]. Because of the $\mathrm{pH}$ equilibrium between the active and inactive forms of these drugs, a large amount of active SN-38 and irinotecan be delivered to the tumor site thanks to the acidic microenvironment of the tumor [65]. For these reasons, liposomal irinotecan (MM-398, formerly known as PEP02) has undergone preclinical and phase I-III testing and was recently approved for use as a second-line treatment for metastatic pancreatic cancer. These trials are outlined in the following sections.

\section{Preclinical studies}

To improve the activation of irinotecan and address issues of overaccumulation in the blood, a liposomal encapsulation of irinotecan (MM-398) was designed to minimize the toxicity of the drug as well as achieve 
a higher efficacy [66]. Drummond et al. utilized highly charged amine groups on a multivalent anionic trapping agent (sucrose octasulfate [SOS] or linear poly(phosphate) $[\mathrm{Pn}]$ ) to encapsulate irinotecan molecules in liposomes. The irinotecan molecules diffused into the liposomes readily; a triethylammonium (TEA) salt was used in a cation exchange mechanism to make up for the influx of drug molecules. Once in the liposome, the irinotecan molecules form a stable complex with the SOS or Pn matrix, effectively allowing for an extremely high drug-to-lipid ratio (109,000 molecules per particle) with a drug release half-life in the circulation of $56.8 \mathrm{~h}$ in Swiss Webster mouse models; these encapsulations will further be referred to as TEA-SOS and TEA-Pn. Synthesis of this stable irinotecan-sucrose octasulfate compound is depicted in Fig. 6. In mouse models, the maximum tolerated dose (MTD) was found to be much higher for nanoliposomal irinotecan (> $320 \mathrm{mg} / \mathrm{kg}$ ) compared to free irinotecan $(80 \mathrm{mg} / \mathrm{kg})$. The efficacy of nanoliposomal irinotecan was also found to be greater than that of free irinotecan in cancer models. All mice with human breast (BT474) xenografts were completely cured of their tumors when treated with the encapsulated form, whereas "notable inhibition of growth" was observed in mice treated with the free form. Mice with human colon (HT29) xenografts treated with nanoliposomal irinotecan also showed significant improvement in survival compared to the free formulation. While the free irinotecan allowed the tumor volume to reach an average of roughly $2000 \mathrm{~mm}^{3}$ in about 35 days posttumor implantation, all regimens involving nanoliposomal irinotecan resulted in an average tumor volume of under $100 \mathrm{~mm}^{3}$ in the same time span. After 66 days

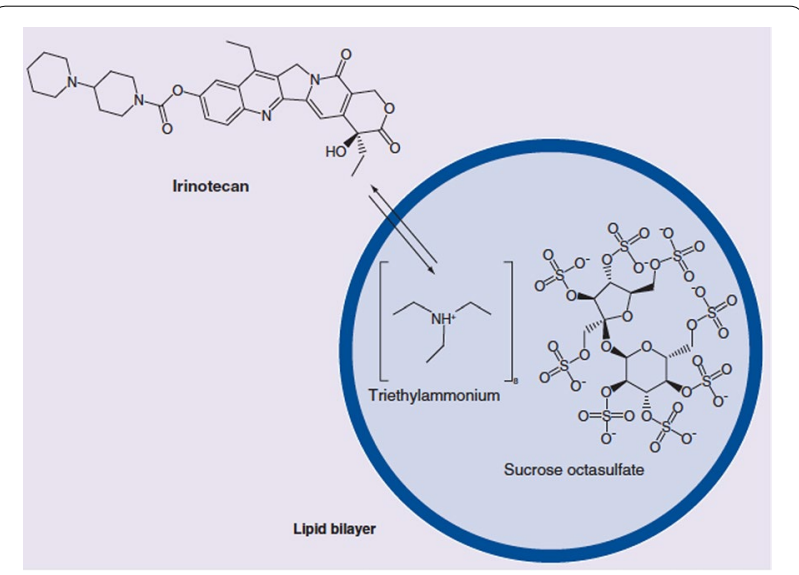

Fig. 6 Depiction of the exchange of triethylamine for irinotecan, which forms a stable complex with sucrose octasulfate inside the liposome (Reproduced with permission from [66]) post tumor implantation, only one of the four nanoliposomal regimes led to a tumor volume similar to that of free irinotecan $(25 \mathrm{mg} / \mathrm{kg}$ of liposomal irinotecan using a TEA-Pn encapsulation), resulting in an average tumor volume of $1750 \mathrm{~mm}^{3}$. The lowest tumor volume found after 66 days was $125 \mathrm{~mm}^{3}$, which was found in mice with a regimen of $50 \mathrm{mg} / \mathrm{kg}$ of liposomal irinotecan with a TEA-SOS encapsulation. None of the mice with colon cancer were found to be tumor free after undergoing the free irinotecan regimen, while 9.1\% $(\mathrm{n}=1)$ and $36.4 \%(\mathrm{n}=4)$ of mice undergoing the 25 and $50 \mathrm{mg} / \mathrm{kg}$ regimens respectively were tumor-free at the end of the study [67].

\section{Phase I}

The goals of these studies were to find the dose-limiting toxicity (DLT), maximum tolerated dose (MTD) and pharmacokinetics (PK) of their respective treatments. The most common symptoms experienced by patients during the phase I trials include vomiting, diarrhea, neutropenia, and leukopenia. The former two symptoms were observed more commonly with low doses of liposomal irinotecan, and the latter two symptoms were more common with high doses of liposomal irinotecan [64, 68]. Summary tables of the most commonly observed symptoms from Chang et al. and Chiang et al. are seen in Table 3.

One study conducted by Chang et al. examined a cycle regimen of intravenous liposomal irinotecan in $90 \mathrm{~min}$ infusions every 3 weeks for a mean of 4 cycles (range 1-6). A total of 11 patients with solid refractory tumors participated in the study. Three different doses were given: $60 \mathrm{mg} / \mathrm{m}^{2}$ (one patient), $120 \mathrm{mg} / \mathrm{m}^{2}$ (six patients), and $180 \mathrm{mg} / \mathrm{m}^{2}$ (four patients). The MTD dose was found to be $120 \mathrm{mg} / \mathrm{m}^{2}$, and the most common treatment-related adverse events (AEs) at this dose were diarrhea $(100 \%$ in all grades, $33 \%$ in grade $3 / 4$ ) and vomiting $(83.3 \%$ in all grades, $66.7 \%$ in grade $3 / 4$ ); see Table $3 \mathrm{~A}$ for a full list of observed symptoms. Only one patient was seen to have a reaction after infusion. This reaction involved chest tightness after the first $30 \mathrm{~min}$ of their infusion during cycle 2, but the patient's vital signs were found to be stable. One treatment-related death was observed-a 67-year-old female patient with small cell carcinoma of the pancreas. This patient died of septic shock, disseminated intravascular coagulopathy and acute respiratory distress syndrome 7 days after first experiencing symptoms (8 days after her first dosing) [64].

Chiang et al. conducted a study to see the effects of giving infusions of liposomal irinotecan followed by infusions of 5-fluorouracil (5-FU) and leucovorin (LV) to 16 patients with solid refractory tumors. Cycles consisted of an infusion of intravenous liposomal irinotecan over a 
Table 3 Drug related adverse effects seen in phase 1 trials of liposomal irinotecan. Reproduced with permission from [64, 68]

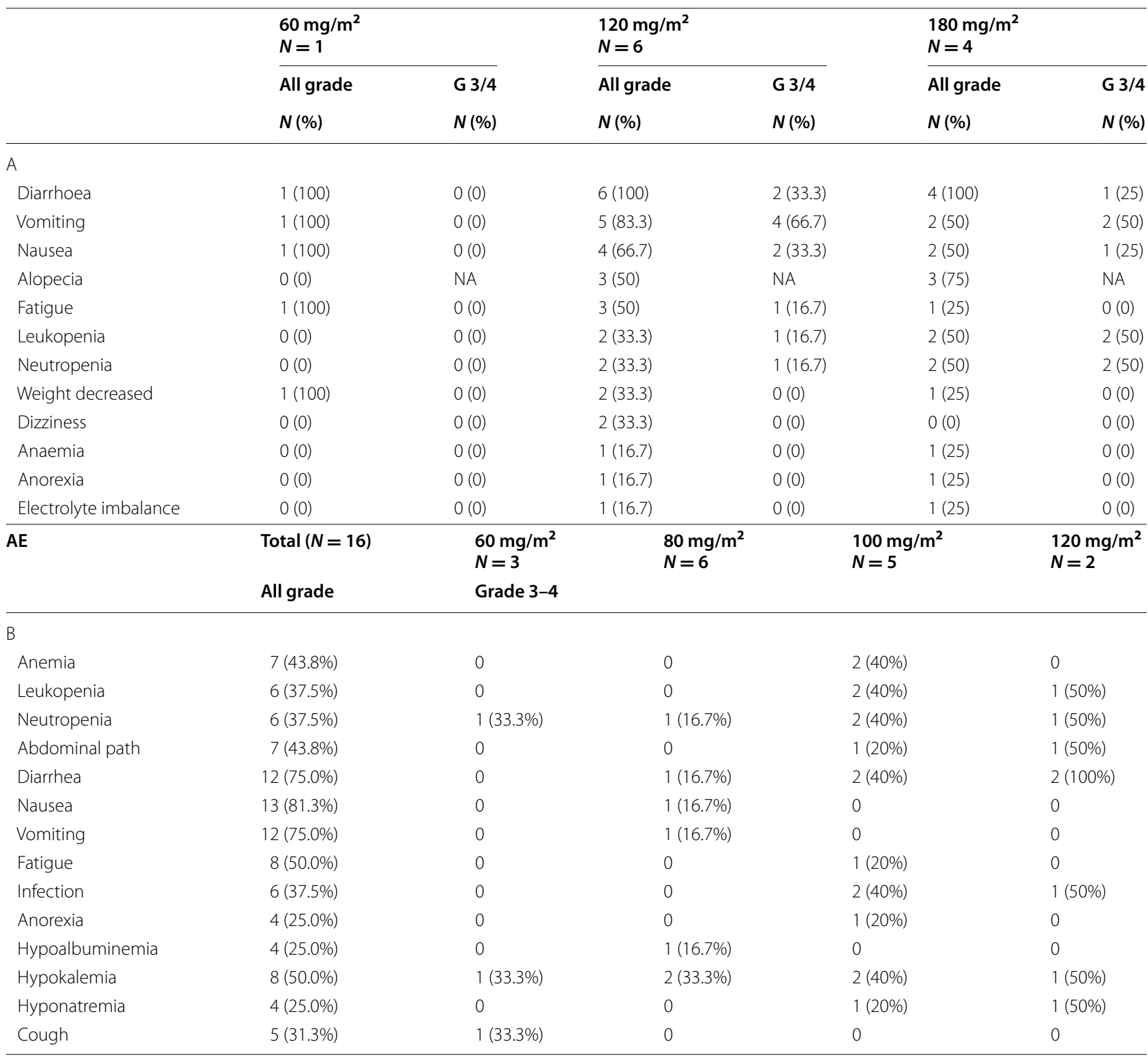

A shows the adverse effects seen in Chang et al's study, while B shows the adverse effects seen in Chiang et al's study

$A E$ adverse event

period of $90 \mathrm{~min}$ followed by $24 \mathrm{~h}$ infusions of $2000 \mathrm{mg} /$ $\mathrm{m}^{2}$ 5-fluorouracil (5-FU) and $200 \mathrm{mg} / \mathrm{m}^{2}$ leucovorin (LV) on days 1 and 8 every 3 weeks. Four different concentrations of liposomal irinotecan were given: $60 \mathrm{mg} /$ $\mathrm{m}^{2}$ (three patients), $80 \mathrm{mg} / \mathrm{m}^{2}$ (six patients), $100 \mathrm{mg} / \mathrm{m}^{2}$ (five patients), and $120 \mathrm{mg} / \mathrm{m}^{2}$ (two patients). The MTD was found to be $80 \mathrm{mg} / \mathrm{m}^{2}$, and the most common treatment-related AEs were nausea (81\%), diarrhea (75\%) and vomiting (69\%) (see Table 3B for a full list of observed symptoms). There were no treatment-related deaths in this study [68].
Phase II

The main goals of the phase II studies were to test percent dosages in humans and to test the efficacy, comparing liposomal irinotecan to the free form of the drug with an emphasis on toxicity.

One randomized study tested the objective response rate (ORR) of liposomal irinotecan in the second-line treatment of advanced oesophago-gastric (OG) cancer [69]. Patients with locally advanced or metastatic OG cancer were randomly assigned to one of three arms as a second-line treatment (having failed one prior 
chemotherapy). These arms were liposomal irinotecan $120 \mathrm{mg} / \mathrm{m}^{2}$, free irinotecan $300 \mathrm{mg} / \mathrm{m}^{2}$, and docetaxel (Taxotere) $75 \mathrm{mg} / \mathrm{m}^{2}$ every 3 weeks, with a total of 44 patients in each arm. Patients in each arm were equally represented in terms of age, sex, country of origin, previous treatment, and primary tumor site (gastric or GO junction). The study found that the time at which $\mathrm{C}_{\max }$ (blood plasma concentration) was reached was much higher for liposomal irinotecan compared to normal irinotecan (10.2 compared to $2.1 \mathrm{~h}$ after infusion), showing that liposomal irinotecan stays active in the bloodstream for longer. The $\mathrm{C}_{\max }$ value of formation of $\mathrm{SN}-38$ was approximately $50 \%$ less after the infusion of liposomal irinotecan, showing that less of the drug was released prematurely when encapsulated. Although a smaller concentration of irinotecan was used in the nanoencapsulated arm than in the free irinotecan arm, the sum of the complete and partial responses was found to be twice as large in the nanoliposomal arm (13.6\% compared to $6.8 \%)$, and the disease control rates were found to be comparable in both arms (59.1\% in the nanoliposomal irinotecan arm and $61.3 \%$ in the free irinotecan arm). Unexpectedly, liposomal irinotecan was also seen to have much higher rates of grade 3 or 4 events of diarrhea and nausea, as seen in Table 4. Lower rates were observed in other studies [70-75], though, and it is to be noted that all other toxicity events had similar rates of occurrence with free irinotecan. It is also to be noted that although the overall survival rate of liposomal irinotecan was the lowest of the three arms, the progression free survival rate was roughly 9 months longer than that of regular irinotecan and nearly four and a half months longer than that of docetaxel (Fig. 7) [69].

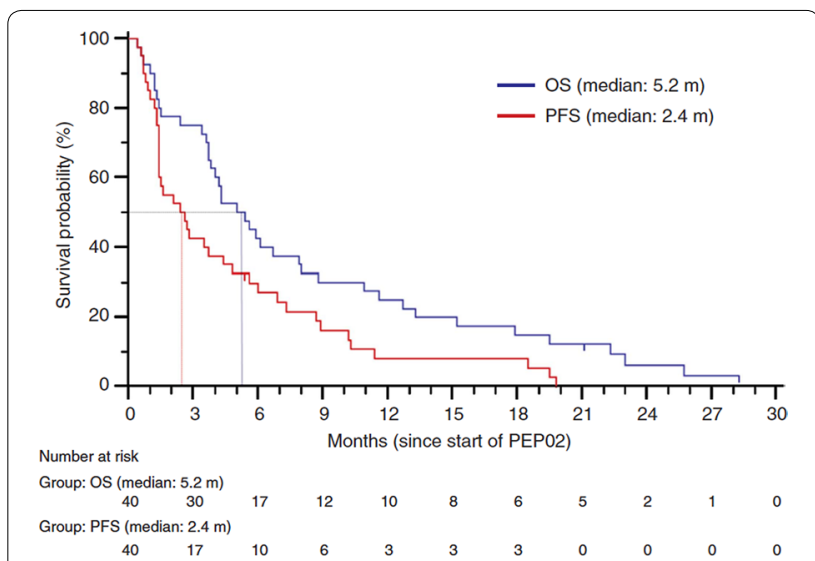

Fig. 7 Kaplan-Meier curves of overall and progression-free survival. Abbreviations used are $m$ for months, OS for overall survival, and PFS for progression-free survival (Reproduced with permission from [76])

A separate, multinational phase II study was conducted using liposomal irinotecan sucrosofate for patients with gemcitabine-refractory metastatic pancreatic cancer, the results of which led to a global phase III trial (NAPOLI-1) [76]. In this trial, a total of 40 patients were given $120 \mathrm{mg} / \mathrm{m}^{2}$ every 3 weeks; 27 of the 40 patients were able to stay at this dose, while 11 patients needed a reduced dose of $100 \mathrm{mg} / \mathrm{m}^{2}$ due to concerns of excess toxicity (mostly asthenia observed in US patients). The median progression-free and overall survival rates were 2.4 and 5.2 months respectively (Fig. 8). An objective response was seen in $7.5 \%$ of patients and disease control (partial response plus stable disease) was seen in $50 \%$ of patients. The most commonly seen adverse event was diarrhea ( $75 \%$ of patients), which the most commonly seen grade 3 or 4 events were neutropenia (30\%)

Table 4 Adverse effects of liposomal irinotecan. Reproduced with permission from [69]

\begin{tabular}{|c|c|c|c|c|c|c|}
\hline & \multicolumn{6}{|c|}{ Most common grade $3-4$ adverse events } \\
\hline & \multicolumn{2}{|c|}{ PEPO2 } & \multicolumn{2}{|c|}{ Irinotecan } & \multicolumn{2}{|c|}{ Docetaxel } \\
\hline & $N$ & $\%$ & $n$ & $\%$ & $n$ & $\%$ \\
\hline Anaemia & 2 & 4.5 & 2 & 4.5 & 3 & 6.8 \\
\hline Neutropaenia & 5 & 11.4 & 7 & 15.9 & 2 & 2.6 \\
\hline Thrombocytopenia & 1 & 2.3 & 1 & 2.3 & 0 & 0 \\
\hline Febrile neutropenia & 3 & 6.8 & 5 & 11.3 & 2 & 2.6 \\
\hline Diarrhoea & 12 & 27.3 & 8 & 18.2 & 1 & 2.3 \\
\hline Nausea & 5 & 11.4 & 2 & 4.6 & 0 & 0 \\
\hline Vomiting & 2 & 4.6 & 6 & 13.6 & 3 & 6.8 \\
\hline Anorexia & 3 & 6.8 & 3 & 6.8 & 0 & 0 \\
\hline Fatigue & 2 & 4.6 & 1 & 2.3 & 1 & 2.3 \\
\hline
\end{tabular}

Most common grade 3-5 adverse events observed in a phase Il study of liposomal irinotecan (PEP02), comprised of a liposomal irinotecan, irinotecan, and docetaxel arm 
a

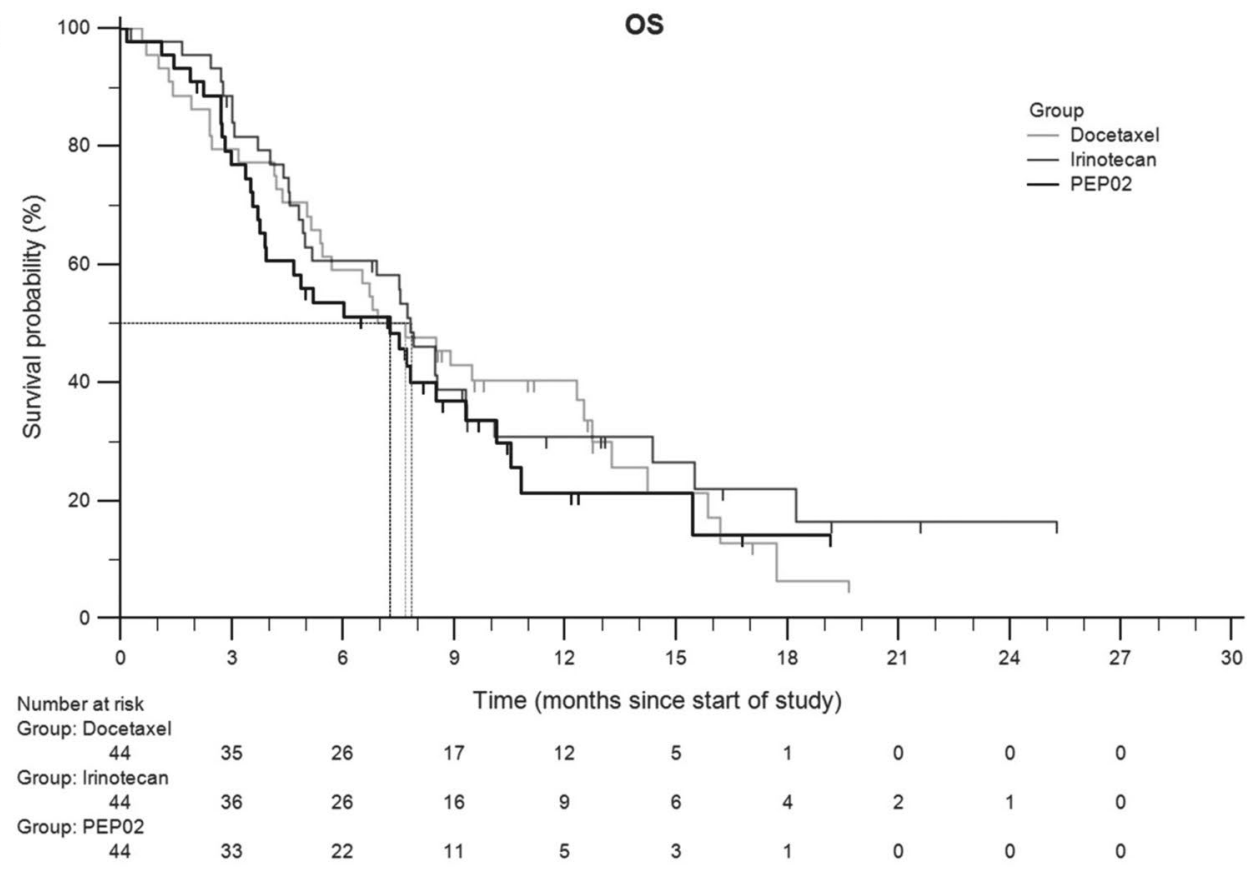

b

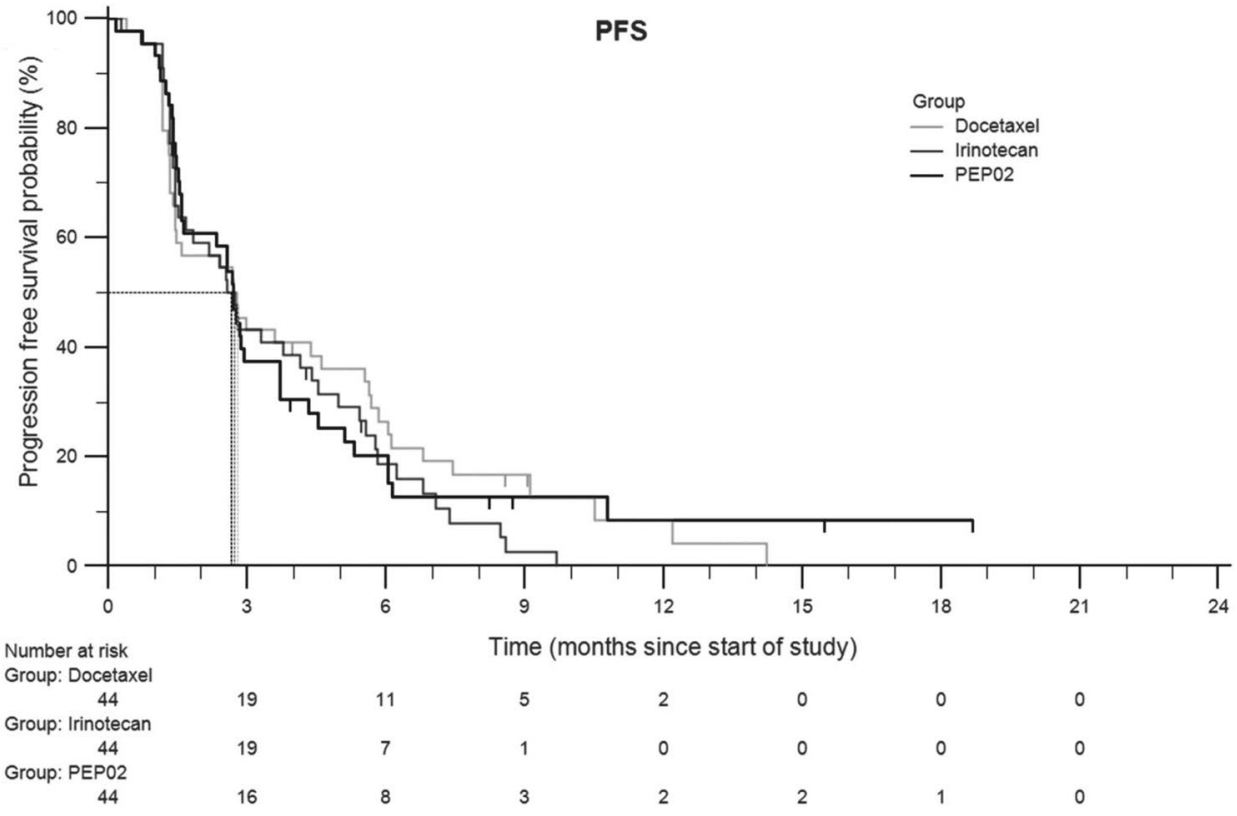

Fig. 8 The Kaplan-Meier estimates of overall and progression-free survival (a, $\mathbf{b}$ respectively) in the intent-to-treat population for liposomal irinotecan (PEP02), irinotecan, and docetaxal (Reproduced with permission from [69])

and leucopenia (25\%). During this study three patients passed within the last 30 days of the last dose given during this study, all of which were due to neutropenia. As stated in Ko et al's discussion, this highlights the need for watchful patient care, especially in such a fragile patient population, but with $75 \%$ of patients surviving at least 3 months, including 25\% reaching the 1 -year mark, liposomal irinotecan was approved to start phase III trials [76].

\section{Phase III}

In a global randomized phase III trial (NAPOLI-1), patients with metastatic pancreatic ductal adenocarcinoma were randomly assigned one of two arms as 
a second-line treatment following the first-line gemcitabine-based treatment [76, 77]. These two arms included a liposomal irinotecan monotherapy $(120 \mathrm{mg} /$ $\mathrm{m}^{2}$ every 3 weeks) and a control arm of fluorouracil (5-FU) given weekly as a 24-h infusion at $2000 \mathrm{mg} /$ $\mathrm{m}^{2}$ and folinic acid (LV) at $200 \mathrm{mg} / \mathrm{m}^{2}$. An additional arm combining MM-398 $\left(80 \mathrm{mg} / \mathrm{m}^{2}\right)$ and 5 -FU $\left(2400 \mathrm{mg} / \mathrm{m}^{2}\right)$ plus LV $\left(400 \mathrm{mg} / \mathrm{m}^{2}\right)$ as a biweekly treatment was added later. Patients in the three arms of the trial were evenly represented in age, sex, region, and Karnofsky performance status score. Patients who received the combination treatment (MM-398+5-FU/ LV) had a median overall survival of 6.1 months (HR:
$0.67 ; \mathrm{p}=0.012)$, in comparison to those given only MM-398 (4.9 months) and those given only 5-FU/LV (4.2 months) (Fig. 9). Thus, no statistically significant difference was observed between the monotherapy and the 5-FU/LV control for median overall survival. Improvements in median progression-free survival (3.1 vs. 1.5 months; HR: $0.56, \mathrm{p}=0.00001$ ), objective response rate $(16 \%$ vs. $1 \%)$, time to treatment failure (2.3 months vs. 1.4 months), and $\geq 50 \%$ decreases in CA $19-9$ marker response (29\% vs. $9 \%$ ) were observed for patients who received the combination arm. Notable grade 3-4 adverse responses for the combination therapy were diarrhea (13\%) and neutropenia

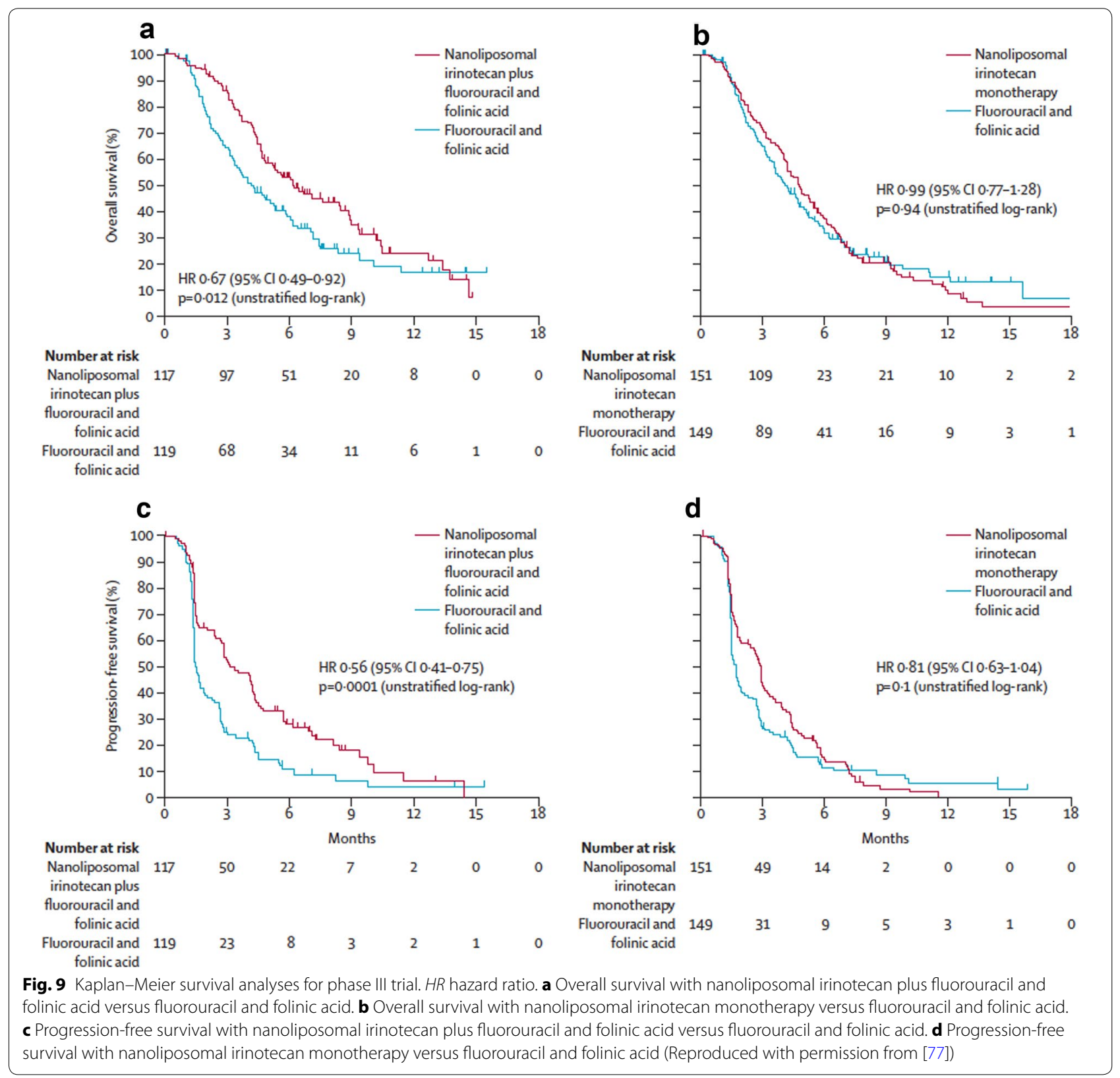


(25\%) (Table 5). Other symptoms including grade 3-4 responses are listed and compared for the three different treatments in Table 5.

\section{Conclusions and future directions}

The advent of nanomedicines represents significant advances in the field of drug delivery. The options for nanoparticle design and function are extremely varied and the list of potential applications continues to grow, to the point where the drug delivery system can be tailormade to best suit the selected drug. However, it is important to remember that nanoparticle-based treatments are not miracle cures. They have both flaws and challenges to overcome. Selective targeting, while heralded as an improvement over non-encapsulated drugs, is a challenge unto itself. While many cancers overexpress surface proteins common in normal cells, overabundance of a specific surface protein is not enough to guarantee selectivity using targeted treatment. Ultimately, some of the drug will end up off-target, affecting non-cancerous cells. Choosing the right surface marker is critical for a targeted treatment to work. For liposomal irinotecan (MM-398), selectivity is achieved through the acidic tumor microenvironment. Irinotecan turns into its more active form, $\mathrm{SN}-38$, in acidic environments. $\mathrm{SN}-38$, then, disrupts the molecular machinery responsible for DNA replication. One could consider this a form of focused targeting: targeting only dividing cells in an acidic environment, such as those found in a tumor. However, tumor cells are not the only actively dividing cells in an acidic environment the body. Stomach epithelial cells are one such example. This may explain why most of the side-effects of MM-398 are digestive-related. Further, the tumor microenvironment is both heterogeneous and complex. The tumor is an amalgamation of both cancer and normal cells. Tumor cells invoke wound-repair pathways, recruiting basal laminal cells, blood vessel cells, and tumor-assisting macrophages (TAMs) to assist with growth and survival [2]. Due to cancer cells having a preference towards anaerobic metabolic pathways as well as the partial hypoxia of the tumor environment, $\mathrm{pH}$ gradients moving from extracellular to intracellular spaces tend to be reversed in tumor tissue when compared to normal tissue [78]. Differentiation between cancer cells within the same tumor can also occur. Due to genome instability, populations of different cancer cells can arise within a single tumor. As many as 20 driver mutations, and anywhere between 1000 and 100,000 point mutations can be found within individual cancers. Treatment may further increase the number of these mutations. "For example, gliomas that recur after treatment with the DNA alkylating agent temozolomide have been shown to carry huge numbers of mutations with a signature typical of such agents" [79].

There is also a reproducibility issue with nanoparticle production. Reproducible, large-scale synthesis of nanomedicines is still a challenge for the distribution of a homogeneous batch of nanomedicines, especially when considering that these nano-platforms often require specific conditions for production via self-assembly. Thorough characterization of these nanomedicines, at every stage of the production process must be enforced to ensure both reproducibility of synthesis and efficacy. Storage of these nanomedicines under appropriate conditions is also critical since colloidal instability can dramatically alter their performance in vivo. Ideal nanomedicines will have a modular design that can be easily scaled up for cGMP manufacturing and stored for a long time prior to use in patients.

Table 5 Adverse effects of MM-398. Reproduced with permission from [77]

\begin{tabular}{|c|c|c|c|c|c|c|}
\hline & \multicolumn{2}{|c|}{$\begin{array}{l}\text { Nanoliposomal irinotecan plus } \\
\text { fluorouracil and folinic acid } \\
\text { combination therapy }(n=117)\end{array}$} & \multicolumn{2}{|c|}{$\begin{array}{l}\text { Nanoliposomal irinotecan } \\
\text { monotherapy }(n=147)\end{array}$} & \multicolumn{2}{|c|}{$\begin{array}{l}\text { Fluorouracil and folinic acid } \\
\text { control }(n=134)\end{array}$} \\
\hline & Any grade & Grades 3-4 & Any grade & Grades 3-4 & Any grade & Grades 3-4 \\
\hline Diarrhoea & 69 (59\%) & $15(13 \%)$ & 103 (70\%) & $31(21 \%)$ & $35(26 \%)$ & $6(4 \%)$ \\
\hline Vomiting & $61(52 \%)$ & $13(11 \%)$ & 80 (54\%) & $20(14 \%)$ & $35(26 \%)$ & $4(3 \%)$ \\
\hline Nausea & $60(51 \%)$ & $9(8 \%)$ & $89(61 \%)$ & $8(5 \%)$ & $46(34 \%)$ & $4(3 \%)$ \\
\hline Decreased appetite & $52(44 \%)$ & $5(4 \%)$ & $72(49 \%)$ & $13(19 \%)$ & $43(32 \%)$ & $3(2 \%)$ \\
\hline Fatigue & $47(40 \%)$ & $16(14 \%)$ & $54(37 \%)$ & $9(6 \%)$ & $37(28 \%)$ & $5(4 \%)$ \\
\hline Neutropenia* & $46(39 \%)$ & $32(27 \%)$ & $37(25 \%)$ & $22(15 \%)$ & $7(5 \%)$ & $2(1 \%)$ \\
\hline Anaemia & $44(38 \%)$ & $11(9 \%)$ & $48(33 \%)$ & $16(11 \%)$ & $31(23 \%)$ & $9(7 \%)$ \\
\hline Hypokalemia & $14(12 \%)$ & $4(3 \%)$ & $32(22 \%)$ & $17(12 \%)$ & $12(9 \%)$ & $3(2 \%)$ \\
\hline
\end{tabular}

Data are number of patients (\%). The table shows grade 3 and 4 adverse events reported in $\geq 5 \%$ of patients whose treatment included nanoliposomal irinotecan with $\geq 2 \%$ incidence versus fluorouracil and folinic acid

* Includes agranulocytosis, febrile neutropenia, granulocytopenia, neutropenia, neutropenic sepsis, decreased neutrophil count, and pancytopenia 
Furthermore, the changes in legislation often occur at a rate different than the development of medicines in the laboratory. One organization, the Nanotechnology Characterization Laboratory, works with the FDA as bridge between scientists and regulatory committees to aid the review of nanomedicines [80] and has helped translation of some nanoplatforms.

Overcoming these challenges may seem like a herculean effort, but it is not impossible. There has been an overall shift in cancer research, from individual-based to a more collaborative approach that has helped achieve success. A complex problem requires a complex solution, and a multidisciplinary approach seems like the best option. Cross collaborations between theoretical and experimental scientists across academia, with the pharmaceutical industry, medical doctors and the regulatory agencies will help translate more findings from the lab to the clinic and usher in the next era of clinical cancer nanomedicines.

\section{Abbreviations \\ EPR: enhanced permeability and retention effect; PEG: polyethylene glycol: RES: reticulo-endothelial system; MPS: mononuclear phagocyte system; BPD: verteporfin; ROS: reactive oxygen species; PLGA: poly(D,L-lactide-co-glycolide); BBB: blood-brain barrier; PRINT: particle replication in nonwetting templates; SWCNT: single walled carbon nanotube; VEGF: vascular endothelial growth factor; $C_{\max }$ : plasma concentration; MM-398: liposomal irinotecan; SOS: sucrose octasulfate; Pn: linear poly(phosphate); TEA: triethylammonium; MTD: maximum tolerated dose; DLT: dose-limiting toxicity; PK: pharmacokinet- ics; AE: adverse effects; 5-FU: 5-fluorouracil; LV: leucovorin; ORR: objective response rate; OG: oesophago-gastric cancer; HR: hazard ratio; TAM: tumor- assisting macrophages; MDR: multi-drug resistance.}

\section{Authors' contributions}

All authors contributed to the design, research, writing, and reviewing of this manuscript. All authors read and approved the final manuscript.

\section{Author details}

${ }^{1}$ Department of Biological Sciences, University of Massachusetts, Lowell, MA 01854, USA. ${ }^{2}$ Department of Chemical Engineering, University of Massachusetts, 1 University ave, Lowell, MA 01854, USA.

\section{Acknowledgements}

Not applicable.

\section{Competing interests}

The authors declare that they have no competing interests.

\section{Availability of data and materials}

Not applicable.

\section{Consent for publication}

Not applicable.

\section{Ethics approval and consent to participate}

Not applicable since no clinical trials were conducted as part of this review manuscript.

\section{Funding}

The authors acknowledge funding from the National Cancer Institute, a part of the National Institutes of Health (Award \# K99CA153948 and R00CA153948).

\section{Publisher's Note}

Springer Nature remains neutral with regard to jurisdictional claims in published maps and institutional affiliations.

Received: 28 August 2017 Accepted: 22 November 2017

Published online: 11 December 2017

\section{References}

1. Siegel RL, Miller KD, Fedewa SA, Ahnen DJ, Meester RG, Barzi A, Jemal A (2017) Colorectal cancer statistics, 2017. CA Cancer J Clin 67(3):177-193

2. Hanahan D, Weinberg RA (2011) Hallmarks of cancer: the next generation. Cell 144(5):646-674

3. Wicki A, Witzigmann D, Balasubramanian V, Huwyler J (2015) Nanomedicine in cancer therapy: challenges, opportunities, and clinical applications. J Control Release 200:138-157

4. Sinha R, Kim GJ, Nie S, Shin DM (2006) Nanotechnology in cancer therapeutics: bioconjugated nanoparticles for drug delivery. Mol Cancer Ther 5(8):1909-1917

5. Albanese A, Tang PS, Chan WC (2012) The effect of nanoparticle size, shape, and surface chemistry on biological systems. Annu Rev Biomed Eng 14:1-16

6. Bregoli L, Movia D, Gavigan-Imedio JD, Lysaght J, Reynolds J, PrinaMello A (2016) Nanomedicine applied to translational oncology: a future perspective on cancer treatment. Nanomed Nanotechnol Biol Med 12(1):81-103

7. Truong NP, Whittaker MR, Mak CW, Davis TP (2015) The importance of nanoparticle shape in cancer drug delivery. Expert Opini Drug Deliv 12(1):129-142

8. Stylianopoulos T, Poh M-Z, Insin N, Bawendi MG, Fukumura D, Munn LL et al (2010) Diffusion of particles in the extracellular matrix: the effect of repulsive electrostatic interactions. Biophys J 99(5):1342-1349

9. Locatelli E, Franchini MC (2012) Biodegradable PLGA-b-PEG polymeric nanoparticles: synthesis, properties, and nanomedical applications as drug delivery system. J Nanopart Res 14(12):1

10. Danhier F, Ansorena E, Silva JM, Coco R, Le Breton A, Préat V (2012) PLGA-based nanoparticles: an overview of biomedical applications. J Controlled Release 161(2):505-522

11. von Roemeling C, Jiang W, Chan CK, Weissman IL, Kim BY (2017) Breaking down the barriers to precision cancer nanomedicine. Trends Biotechnol 35(2):159-171

12. Cho K, Wang X, Nie S, Chen ZG, Shin DM (2008) Therapeutic nanoparticles for drug delivery in cancer. Clin Cancer Res 14(5):1310-1316

13. Gao W, Chan JM, Farokhzad OC (2010) pH-responsive nanoparticles for drug delivery. Mol Pharm 7(6):1913-1920

14. Yang J, Duan Y, Zhang X, Wang Y, Yu A (2016) Modulating the cellular microenvironment with disulfide-containing nanoparticles as an auxiliary cancer treatment strategy. J Mater Chem B 4(22):3868-3873

15. Balendiran GK, Dabur R, Fraser D (2004) The role of glutathione in cancer. Cell Biochem Funct 22(6):343-352

16. Chen K-J, Liang H-F, Chen H-L, Wang Y, Cheng P-Y, Liu H-L et al (2012) A thermoresponsive bubble-generating liposomal system for triggering localized extracellular drug delivery. ACS Nano 7(1):438-446

17. Jhaveri A, Deshpande P, Torchilin V (2014) Stimuli-sensitive nanopreparations for combination cancer therapy. J Control Release 190:352-370

18. Rapoport N, Gao Z, Kennedy A (2007) Multifunctional nanoparticles for combining ultrasonic tumor imaging and targeted chemotherapy. J Natl Cancer Inst 99(14):1095-1106

19. Guduru R, Liang P, Runowicz C, Nair M, Atluri V, Khizroev S (2013) Magneto-electric nanoparticles to enable field-controlled high-specificity drug delivery to eradicate ovarian cancer cells. Sci Rep 3:2953

20. Konan-Kouakou YN, Boch R, Gurny R, Allemann E (2005) In vitro and in vivo activities of verteporfin-loaded nanoparticles. J Control Release 103(1):83-91

21. Wang L, Shi C, Wright FA, Guo D, Wang X, Wang D et al (2017) Multifunctional telodendrimer nanocarriers restore synergy of bortezomib and doxorubicin in ovarian cancer treatment. Can Res 77(12):3293-3305 
22. Meng H, Mai WX, Zhang H, Xue M, Xia T, Lin S et al (2013) Codelivery of an optimal drug/siRNA combination using mesoporous silica nanoparticles to overcome drug resistance in breast cancer in vitro and in vivo. ACS Nano 7(2):994-1005

23. Ananta JS, Paulmurugan R, Massoud TF (2016) Tailored nanoparticle codelivery of antimiR-21 and antimiR-10b augments glioblastoma cell kill by temozolomide: toward a "personalized" anti-microRNA therapy. Mol Pharm 13(9):3164-3175

24. Ahmed N, Fessi H, Elaissari A (2012) Theranostic applications of nanoparticles in cancer. Drug Discov Today 17(17):928-934

25. Rai P, Mallidi S, Zheng X, Rahmanzadeh R, Mir Y, Elrington S et al (2010) Development and applications of photo-triggered theranostic agents. Adv Drug Deliv Rev 62(11):1094-1124

26. Garcia KP, Zarschler K, Barbaro L, Barreto JA, O'Malley W, Spiccia L et al (2014) Zwitterionic-coated "Stealth" nanoparticles for biomedical applications: recent advances in countering biomolecular corona formation and uptake by the mononuclear phagocyte system. Small 10(13):2516-2529

27. Miele E, Spinelli GP, Miele E, Tomao F, Tomao S (2009) Albumin-bound formulation of paclitaxel (Abraxane $\left.{ }^{\circledR} \mathrm{ABI}-007\right)$ in the treatment of breast cancer. Int J Nanomed 4:99

28. Rodriguez PL, Harada T, Christian DA, Pantano DA, Tsai RK, Discher DE (2013) Minimal "Self" peptides that inhibit phagocytic clearance and enhance delivery of nanoparticles. Science 339(6122):971-975

29. Duan X, LiY (2013) Physicochemical characteristics of nanoparticles affect circulation, biodistribution, cellular internalization, and trafficking. Small 9(9-10):1521-1532

30. Toy R, Hayden E, Shoup C, Baskaran H, Karathanasis E (2011) The effects of particle size, density and shape on margination of nanoparticles in microcirculation. Nanotechnology 22(11):115101

31. Toy R, Peiris PM, Ghaghada KB, Karathanasis E (2014) Shaping cancer nanomedicine: the effect of particle shape on the in vivo journey of nanoparticles. Nanomedicine 9(1):121-134

32. Yuan H, Takeuchi E, Salant DJ (2002) Podocyte slit-diaphragm protein nephrin is linked to the actin cytoskeleton. Am J Physiol Renal Physiol 282(4):F585-F591

33. Liu J, Yu M, Zhou C, Zheng J (2013) Renal clearable inorganic nanoparticles: a new frontier of bionanotechnology. Mater Today 16(12):477-486

34. Ruggiero A, Villa CH, Bander E, Rey DA, Bergkvist M, Batt CA et al (2010) Paradoxical glomerular filtration of carbon nanotubes. Proc Natl Acad Sci 107(27):12369-12374

35. Stylianopoulos T, Wong C, Bawendi MG, Jain RK, Fukumura D (2012) Multistage nanoparticles for improved delivery into tumor tissue. Methods Enzymol 508:109

36. Pardridge WM (2005) The blood-brain barrier: bottleneck in brain drug development. NeuroRx. 2(1):3-14

37. Ulbrich K, Hekmatara T, Herbert E, Kreuter J (2009) Transferrin-and transferrin-receptor-antibody-modified nanoparticles enable drug delivery across the blood-brain barrier (BBB). Eur J Pharm Biopharm 71(2):251-256

38. Kreuter J (2013) Mechanism of polymeric nanoparticle-based drug transport across the blood-brain barrier (BBB). J Microencapsul 30(1):49-54

39. Michaelis K, Hoffmann M, Dreis S, Herbert E, Alyautdin R, Michaelis M et al (2006) Covalent linkage of apolipoprotein e to albumin nanoparticles strongly enhances drug transport into the brain. J Pharmacol Exp Ther 317(3):1246-1253

40. Hu K, Li J, Shen Y, Lu W, Gao X, Zhang Q et al (2009) Lactoferrin-conjugated PEG-PLA nanoparticles with improved brain delivery: in vitro and in vivo evaluations. J Control Release 134(1):55-61

41. Kim HR, Gil S, Andrieux K, Nicolas V, Appel M, Chacun H et al (2007) Low-density lipoprotein receptor-mediated endocytosis of PEGylated nanoparticles in rat brain endothelial cells. Cell Mol Life Sci 64(3):356-364

42. Shilo M, Sharon A, Baranes K, Motiei M, Lellouche J-PM, Popovtzer R (2015) The effect of nanoparticle size on the probability to cross the blood-brain barrier: an in vitro endothelial cell model. J Nanobiotechnol 13(1):19

43. Lockman PR, Koziara JM, Mumper RJ, Allen DD (2004) Nanoparticle surface charges alter blood-brain barrier integrity and permeability. J Drug Target 12(9-10):635-641
44. ShankerSharma H, Sharma A (2012) Neurotoxicity of engineered nanoparticles from metals. CNS Neurol Disord Drug Targets 11(1):65-80

45. Xue Y, Wu J, Sun J (2012) Four types of inorganic nanoparticles stimulate the inflammatory reaction in brain microglia and damage neurons in vitro. Toxicol Lett 214(2):91-98

46. Blanco E, Shen H, Ferrari M (2015) Principles of nanoparticle design for overcoming biological barriers to drug delivery. Nat Biotechnol 33(9):941-951

47. Chauhan VP, Stylianopoulos T, Martin JD, Popović Z, Chen O, Kamoun WS et al (2012) Normalization of tumour blood vessels improves the delivery of nanomedicines in a size-dependent manner. Nat Nanotechnol 7(6):383-388

48. Huang S, Shao K, Liu Y, Kuang Y, Li J, An S et al (2013) Tumor-targeting and microenvironment-responsive smart nanoparticles for combination therapy of antiangiogenesis and apoptosis. ACS Nano 7(3):2860-2871

49. Sun T, Zhang YS, Pang B, Hyun DC, Yang M, Xia Y (2014) Engineered nanoparticles for drug delivery in cancer therapy. Angew Chem Int Ed 53(46):12320-12364

50. Alley SC, Okeley NM, Senter PD (2010) Antibody-drug conjugates: targeted drug delivery for cancer. Curr Opin Chem Biol 14(4):529-537

51. Senter PD (2009) Potent antibody drug conjugates for cancer therapy. Curr Opin Chem Biol 13(3):235-244

52. Puri A, Loomis K, Smith B, Lee J-H, Yavlovich A, Heldman E et al (2009) Lipid-based nanoparticles as pharmaceutical drug carriers: from concepts to clinic. Crit Rev ${ }^{\text {TM }}$ Ther Drug Carrier Syst 26(6):523-580

53. Yatvin MB, Weinstein JN, Dennis WH, Blumenthal R (1978) Design of liposomes for enhanced local release of drugs by hyperthermia. Science 202(4374):1290-1293

54. Frenkel V (2008) Ultrasound mediated delivery of drugs and genes to solid tumors. Adv Drug Deliv Rev 60(10):1193-1208

55. Xu J, Luft JC, Yi X, Tian S, Owens G, Wang J et al (2013) RNA replicon delivery via lipid-complexed PRINT protein particles. Mol Pharm 10(9):3366-3374

56. Hoare TR, Kohane DS (2008) Hydrogels in drug delivery: progress and challenges. Polymer 49(8):1993-2007

57. Kam NWS, Liu Z, Dai H (2005) Functionalization of carbon nanotubes via cleavable disulfide bonds for efficient intracellular delivery of siRNA and potent gene silencing. J Am Chem Soc 127(36):12492-12493

58. Son KH, Hong JH, Lee JW (2016) Carbon nanotubes as cancer therapeutic carriers and mediators. Int J Nanomed 11:5163

59. Rao A, Richter E, Bandow S, Chase B, Eklund P, Williams K et al (1997) Diameter-selective Raman scattering from vibrational modes in carbon nanotubes. Science 275(5297):187-191

60. Almajhdi F, Fouad H, Khalil K, Awad H, Mohamed S, Elsarnagawy T et al (2014) In-vitro anticancer and antimicrobial activities of PLGA/ silver nanofiber composites prepared by electrospinning. J Mater Sci 25(4):1045-1053

61. Elbaz NM, Ziko L, Siam R, Mamdouh W (2016) Core-shell silver/polymeric nanoparticles-based combinatorial therapy against breast cancer in-vitro. Sci Rep 6:30729

62. Hsiang Y-H, Hertzberg R, Hecht S, Liu L (1985) Camptothecin induces protein-linked DNA breaks via mammalian DNA topoisomerase I. J Biol Chem 260(27):14873-14878

63. Hsiang Y-H, Lihou MG, Liu LF (1989) Arrest of replication forks by drugstabilized topoisomerase I-DNA cleavable complexes as a mechanism of cell killing by camptothecin. Can Res 49(18):5077-5082

64. Chang T, Shiah H, Yang C, Yeh K, Cheng A, Shen B et al (2015) Phase I study of nanoliposomal irinotecan (PEP02) in advanced solid tumor patients. Cancer Chemother Pharmacol 75(3):579

65. Zamboni WC, Jung LL, Egorin MJ, Hamburger DR, Joseph E, Jin R et al (2005) Relationship between plasma exposure of 9-nitrocamptothecin and its 9-aminocamptothecin metabolite and antitumor response in mice bearing human colon carcinoma xenografts. Clin Cancer Res 11(13):4867-4874

66. Carnevale J, Ko AH (2016) MM-398 (nanoliposomal irinotecan): emergence of a novel therapy for the treatment of advanced pancreatic cancer. Future Oncol 12(4):453-464

67. Drummond DC, Noble CO, Guo Z, Hong K, Park JW, Kirpotin DB (2006) Development of a highly active nanoliposomal irinotecan using a novel intraliposomal stabilization strategy. Can Res 66(6):3271-3277 
68. Chiang N-J, Chao T-Y, Hsieh R-K, Wang C-H, Wang Y-W, Yeh CG et al (2016) A phase I dose-escalation study of PEP02 (irinotecan liposome injection) in combination with 5-fluorouracil and leucovorin in advanced solid tumors. BMC Cancer 16(1):907

69. Roy A, Park S, Cunningham D, Kang Y, Chao Y, Chen L et al (2013) A randomized phase II study of PEP02 (MM-398), irinotecan or docetaxel as a second-line therapy in patients with locally advanced or metastatic gastric or gastro-oesophageal junction adenocarcinoma. Ann Oncol 24(6):1567-1573

70. ClinicalTrials.gov (2000) National Library of Medicine (US), Bethesda. Identifier NCT03088813. Study of irinotecan liposome injection (ONIVYDE ${ }^{\circledR}$ ) in patients with small cell lung cancer; 2017 Mar 9 [about 8 screens]. https://clinicaltrials.gov/ct2/show/NCT03088813?term $=\mathrm{mm} 3$ $98 \&$ draw $=2 \&$ rank $=6$. Accessed 6 July 2017

71. ClinicalTrials.gov (2000) National Library of Medicine (US), Bethesda. Identifier NCT02769962. Trial of CRLX101, a nanoparticle camptothecin with olaparib in people with relapsed/refractory small cell lung cancer; 2016 May 11 [about 11 screens]. https://clinicaltrials.gov/ct2/show/NCT 02769962?term $=C R L X 101 \& d r a w=1 \&$ rank=4. Accessed 6 July 2017

72. ClinicalTrials.gov (2000) National Library of Medicine (US), Bethesda. Identifier NCT01612546. Pilot trial of CRLX101 in treatment of patients with advanced or metastatic stomach, gastroesophageal, or esophageal cancer that cannot be removed by surgery; 2012 June 4 [about 7 screens]. https://clinicaltrials.gov/ct2/show/NCT01612546?term $=$ CRLX $101 \&$ draw $=1 \&$ rank=3. Accessed 6 July 2017

73. ClinicalTrials.gov (2000) National Library of Medicine (US), Bethesda. Identifier NCT02680535. MRI/US fusion imaging and biopsy in combination with nanoparticle directed focal therapy for ablation of prostate tissue; 2016 Feb 2 [about 6 screens]. https://clinicaltrials.gov/ct2/show/ NCT02680535?term =AuroLase\&rank=3. Accessed 6 July 2017

74. Pan X, Lee R (2017) Construction of anti-EGFR immunoliposomes via folate-folate binding protein affinity. Int J Pharm 336(2):276-283

75. ClinicalTrials.gov (2000) National Library of Medicine (US), Bethesda. Identifier NCT02856685. A study of mitoxantrone hydrochloride liposome infusion; 2016 Aug 1 [about 7 screens]. https://clinicaltrials.gov/ ct2/show/NCT02856685. Accessed 6 July 2017

76. Ko A, Tempero M, Shan Y, Su W, Lin Y, Dito E et al (2013) A multinational phase 2 study of nanoliposomal irinotecan sucrosofate (PEP02, MM-398) for patients with gemcitabine-refractory metastatic pancreatic cancer. Br J Cancer 109(4):920-925

77. Wang-Gillam A, Li C-P, Bodoky G, Dean A, Shan Y-S, Jameson G et al (2016) Nanoliposomal irinotecan with fluorouracil and folinic acid in metastatic pancreatic cancer after previous gemcitabine-based therapy (NAPOLI-1): a global, randomised, open-label, phase 3 trial. Lancet 387(10018):545-557

78. Stubbs M, Rodrigues L, Howe FA, Wang J, Jeong K-S, Veech RL et al (1994) Metabolic consequences of a reversed $\mathrm{pH}$ gradient in rat tumors. Cancer Res 54(15):4011-4016

79. Stratton MR, Campbell PJ, Futreal PA (2009) The cancer genome. Nature 458(7239):719-724

80. Tinkle S, McNeil SE, Mühlebach S, Bawa R, Borchard G, Barenholz YC, Tamarkin L, Desai N (2014) Nanomedicines: addressing the scientific and regulatory gap. Ann NY Acad Sci 1313:35-56

81. Ma MK, Zamboni WC, Radomski KM, Furman WL, Santana VM, Houghton PJ et al (2000) Pharmacokinetics of irinotecan and its metabolites SN-38 and APC in children with recurrent solid tumors after protracted low-dose irinotecan. Clin Cancer Res 6(3):813-819

82. Cainelli F, Vallone A (2009) Safety and efficacy of pegylated liposomal doxorubicin in HIV-associated Kaposi's sarcoma. Biologics 3:385

83. Chen L, Shiah H, Chao T, Hsieh R, Chen G, Chang J et al (2010) Phase I study of liposome irinotecan (PEP02) in combination with weekly infusion of 5-FU/LV in advanced solid tumors. J Clin Oncol 28(15):e13024

84. Conner JB, Bawa R, Nicholas M, Weinstein V (2014) Copaxone ${ }^{\circledR}$ in the era of biosimilars and nanosimilars. Handbook of Clinical Nanomedicine-From Bench too Bedside. Pan Stanford Publishing Pte Ltd., Singapore, pp 1-31

85. Kim T-Y, Kim D-W, Chung J-Y, Shin SG, Kim S-C, Heo DS et al (2004) Phase I and pharmacokinetic study of Genexol-PM, a cremophor-free, polymeric micelle-formulated paclitaxel, in patients with advanced malignancies. Clin Cancer Res 10(11):3708-3716
86. Ledet G, Mandal TK (2012) Nanomedicine: emerging therapeutics for the 21st century. US Pharm 37(3):7-11

87. Silverman JA, Deitcher SR (2013) Marqibo ${ }^{\circledR}$ (vincristine sulfate liposome injection) improves the pharmacokinetics and pharmacodynamics of vincristine. Cancer Chemother Pharmacol 71(3):555-564

88. Bayever E, Dhindsa N, Fitzgerald JB, Laivins P, Moyo V, Niyikiza C (2013) Méthodes de traitement du cancer du pancréas à l'aide de polythérapies comportant l'irinotécan en liposome. Patent number WO2013188586 A1

89. ClinicalTrials.gov (2000) National Library of Medicine (US), Bethesda. Identifier NCT03020017. NU-0129 in treating patients with recurrent glioblastoma or gliosarcoma undergoing surgery. 2017 Jan 11 [about 7 screens]. https://clinicaltrials.gov/ct2/show/NCT03020017?term=NU0129\&rank=1. Accessed 6 July 2017

90. NCI Drug Dictionary: spherical nucleic acid nanoparticle NU-0129. National Cancer Institute. National Institute of Health. https://www. cancer.gov/publications/dictionaries/cancer-drug?cdrid=786841. Accessed 6 July 2017

91. ClinicalTrials.gov (2000) National Library of Medicine (US), Bethesda. Identifier NCT02551991. Study of nanoliposomal irinotecan (Nal-IRI)containing regimens in patients with previously untreated, metastatic pancreatic adenocarcinoma; 2015 Sep 10 [about 6 screens]. https:// clinicaltrials.gov/ct2/show/NCT02551991?term $=$ mm398\&draw $=2 \& \mathrm{r}$ ank=7. Accessed 6 July 2017

92. ClinicalTrials.gov (2000) National Library of Medicine (US), Bethesda. Identifier NCT02013336. Phase 1 study of MM-398 plus cyclophosphamide in pediatric solid tumors; 2013 Dec 11 [about 6 screen]. https:// clinicaltrials.gov/ct2/show/NCT02013336?term $=$ mm398\&draw $=2 \& \mathrm{r}$ ank $=1$. Accessed 6 July 2017

93. ClinicalTrials.gov (2000) National Library of Medicine (US), Bethesda. Identifier NCT01770795 A phase II trial of Genexol-PM and gemcitabine in patients with advanced non-small-cell lung cancer; 2013 Jan 16 [about 5 screens]. https://clinicaltrials.gov/ct2/show/ NCT01770795?term $=$ Genexol-PM\&draw $=1 \&$ rank=5. Accessed 6 July 2017

94. ClinicalTrials.gov (2000) National Library of Medicine (US), Bethesda. Identifier NCT01784120. A phase II trial of doxorubicin and genexol-PM in patients with advanced breast cancer; 2013 Jan 20 16; [about 5 screens]. https://clinicaltrials.gov/ct2/show/ NCT01784120?term =Genexol-PM\&draw $=1 \&$ rank=6. Accessed 6 July 2017

95. ClinicalTrials.gov (2000) National Library of Medicine (US), Bethesda. Identifier NCT02739633. Study of weekly Genexol ${ }^{\circledR}$-PM plus gemcitabine in subjects with recurrent and metastatic adenocarcinoma of the pancreas; 2016 Mar 21 [about 6 screens]. https://clinicaltrials.gov/ct2/ show/NCT02739633?term $=$ Genexol-PM\&draw $=1 \&$ rank $=2$. Accessed 6 July 2017

96. ClinicalTrials.gov (2000) National Library of Medicine (US), Bethesda. Identifier NCT03008512. A phase II study of weekly Genexol-PM in patients with hepatocelluar carcinoma after failure of sorafenib; 2016 Dec 29 [about 6 screens]. https://clinicaltrials.gov/ct2/show/ NCT03008512?term $=$ Genexol-PM\&draw $=1 \&$ rank=3. Accessed 6 July 2017

97. Young C, Schluep T, Hwang J, Eliasof S (2011) CRLX101 (formerly IT-101) - a novel nanopharmaceutical of camptothecin in clinical development. Current Bioactive Compd 7(1):8-14

98. ClinicalTrials.gov (2000) National Library of Medicine (US), Bethesda. Identifier NCT02187302. CRLX101 in combination with bevacizumab for metastatic renal cell carcinoma (mRCC) versus standard of care (SOC); 2014 June 30 [about 7 screens]. https://clinicaltrials.gov/ct2/ show $/$ NCT02187302?term $=C R L X 101 \& d r a w=1 \&$ rank $=8$. Accessed 6 July 2017

99. ClinicalTrials.gov (2000) National Library of Medicine (US), Bethesda. Identifier NCT01652079. CRLX101 in combination with bevacizumab for recurrent ovarian/tubal/peritoneal cancer; 201 July 25 [about 5 screens]. https:/clinicaltrials.gov/ct2/show/NCT01652079?term=CRLX $101 \&$ draw $=1 \&$ rank=7. Accessed 6 July 2017

100. ClinicalTrials.gov (2000) National Library of Medicine (US), Bethesda. Identifier NCT01380769. A phase 2 study of CRLX101 in patients with advanced non-small cell lung cancer; 2011 June 22 [about 7 screens]. 
https://linicaltrials.gov/ct2/show/NCT01380769?term =CRLX101\&dra $W=1$ \&rank $=2$. Accessed 6 July 2017

101. ClinicalTrials.gov (2000) National Library of Medicine (US), Bethesda. Identifier NCT02389985. A study of CRLX101 in combination with weekly paclitaxel in patients with recurrent or persistent epithelial ovarian, fallopian tube or primary peritoneal cancer; 2015 Mar 2 [about 6 screens]. https://clinicaltrials.gov/ct2/show/NCT02389985?term =CRL $\mathrm{X} 101 \&$ draw $=1 \&$ rank=1. Accessed 6 July 2017

102. Anselmo AC, Mitragotri S (2015) A review of clinical translation of inorganic nanoparticles. AAPS J 17(5):1041-1054

103. ClinicalTrials.gov (2000) National Library of Medicine (US), Bethesda. Identifier NCT00848042. Pilot study of AuroLase(tm) therapy in refractory and/or recurrent tumors of the head and neck; 2009 Feb 19 [about 5 screens]. https://clinicaltrials.gov/ct2/show/NCT00848042?term=Aur oLase\&rank=1. Accessed 6 July 2017

104. ClinicalTrials.gov (2000) National Library of Medicine (US), Bethesda. Identifier NCT021 10069. Paclitaxel albumin-stabilized nanoparticle formulation in treating older patients with locally advanced or metastatic breast cancer; 2014 Apr 8 [about 10 screens]. https://clinicaltrials.gov/ ct2/show/NCT021 10069?term=Vincristine+Sulfate\&draw $=2 \&$ rank=14 Accessed 6 July 2017

105. ClinicalTrials.gov (2000) National Library of Medicine (US), Bethesda. Identifier NCT01355445. Vincristine and irinotecan with or without temozolomide in children and adults with refractory/relapsed rhabdomyosarcoma (VIT-0910); 2011 May 16 [about 10 screens]. https:// clinicaltrials.gov/ct2/show/NCT01355445?term =Vincristine+Sulfate\&dr aw $=2 \&$ rank $=16$. Accessed 6 July 2017

106. ClinicalTrials.gov (2000) National Library of Medicine (US), Bethesda. Identifier NCT02337478. Vincristine sulfate liposome in treating patients with relapsed or refractory acute myeloid leukemia; 2015 Jan 9 [about 6 screens]. https://clinicaltrials.gov/ct2/show/NCT02337478?term=Vincri stine+Sulfate\&draw $=1 \&$ rank=3. Accessed 6 July 2017

107. ClinicalTrials.gov (2000) National Library of Medicine (US), Bethesda. Identifier NCT02879643. Vincristine sulfate liposome injection (Margibo ${ }^{\circledR}$ ) in combination with UK ALL R3 induction chemotherapy for children, adolescents, and young adults with relapsed ALL; 2016 Aug 16 [about 7 screens]. https://clinicaltrials.gov/ct2/show/NCT02879643?ter $m=$ Vincristine + Sulfate\&draw $=1$ \&rank $=4$. Accessed 6 July 2017

108. ClinicalTrials.gov (2000) National Library of Medicine (US), Bethesda. Identifier NCT02257242. vincristine sulfate liposome injection $\left(\right.$ Marqibo $\left.{ }^{\circledR}\right)$, bendamustine and rituximab - phase I trial in indolent B-cell lymphoma (BRiM); 2014 Sep 30 [about 7 screens]. https://clinicaltrials.gov/ct2/show/NCT02257242?term =Vincristine+Sulfate\&draw $=1$ \&rank=10. Accessed 6 July 2017

109. Pan X, Lee RJ (2007) Construction of anti-EGFR immunoliposomes via folate-folate binding protein affinity. Int J Pharm 336(2):276-283

110. ClinicalTrials.gov (2000) National Library of Medicine (US), Bethesda. Identifier NCT02833766. Anti-EGFR-immunoliposomes loaded with doxorubicin in patients with advanced triple negative EGFR positive breast cancer; 2016 July 12 [about 8 screens]. https://clinicaltrials.gov/ ct2/show/NCT02833766?term=Anti-EGFR+immunoliposome\&rank=2. Accessed 6 July 2017

111. Li C, Zhao X, Deng C, Wang C, Wei N, Cui J (2014) Pegylated liposomal mitoxantrone is more therapeutically active than mitoxantrone in L1210 ascitic tumor and exhibits dose-dependent activity saturation effect. Int J Pharm 460(1):165-172

112. Li C, Cui J, Wang C, Li Y, Zhang H, Wang J, Li Y, Zhang L, Zhang L, Guo W, Wang Y (2008) Encapsulation of mitoxantrone into pegylated SUVs enhances its antineoplastic efficacy. Eur J Pharm Biopharm 70(2):657-665

113. ClinicalTrials.gov (2000) National Library of Medicine (US), Bethesda. Identifier NCT02597387. Clinical trial of mitoxantrone HCL liposome injection in patients with relapsed DLBCL and PT/NKCLs; 2015 Nov 3 [about 5 screens]. https://www.clinicaltrials.gov/ct2/show/NCT0259738 7?term $=$ Mitoxantrone $+\mathrm{HCL}+$ Liposome+Injection\&rank=1. Accessed 6 July 2017

114. ClinicalTrials.gov (2000) National Library of Medicine (US), Bethesda. Identifier NCT02596373. A study of mitoxantrone hydrochloride liposome injection in advanced recurrent or metastatic breast cancer; 2015 Nov 2 [about 5 screens]. https://www.clinicaltrials.gov/ct2/show/NCT 02596373?term =Mitoxantrone $+\mathrm{HCL}+$ Liposome+Injection\&rank=4. Accessed 6 July 2017

115. Cortes JE, Goldberg SL, Feldman EJ, Rizzeri DA, Hogge DE, Larson M et al (2015) Phase II, multicenter, randomized trial of CPX-351 (cytarabine: daunorubicin) liposome injection versus intensive salvage therapy in adults with first relapse AML. Cancer 121(2):234-242

116. ClinicalTrials.gov (2000) National Library of Medicine (US), Bethesda. Identifier NCT02138955. A phase IB dose escalation study of lipocurc in patients with cancer; 2014 May 14 [about 7 screens]. https://clinicaltrials.gov/ct2/show/NCT02138955. Accessed 6 July 2017

117. Senzer N, Nemunaitis J, Nemunaitis D, Bedell C, Edelman G, Barve M et al (2013) Phase I study of a systemically delivered p53 nanoparticle in advanced solid tumors. Mol Ther 21(5):1096-1103

118. ClinicalTrials.gov (2000) National Library of Medicine (US), Bethesda. Identifier NCT02340156. Phase II study of combined temozolomide and SGT-53 for treatment of recurrent glioblastoma; 2014 Dec 18 [about 7 screens]. https://clinicaltrials.gov/ct2/show/NCT02340156?term=SGT53\&rank=2. Accessed 6 July 2017

119. ClinicalTrials.gov (2000) National Library of Medicine (US), Bethesda. Identifier NCT02354547. A study of SGT-53 in children with refractory or recurrent solid tumors; 2014 Dec 18 [about 7 screens]. https://clinicaltrials.gov/ct2/show/NCT02354547?term=SGT-53\&rank=3. Accessed 6 July 2017

120. ClinicalTrials.gov (2000) National Library of Medicine (US), Bethesda. Identifier NCT02340117. Study of combined SGT-53 plus gemcitabine/ nab-paclitaxel for metastatic pancreatic cancer; 2014 Dec 18 [about 8 screens]. https://clinicaltrials.gov/ct2/show/NCT02340117?term=SGT53\&rank=4. Accessed 6 July 2017

121. LiPlaCis (2017) Oncology venture. http://www.oncologyventure.com/ pipeline/liplacis/. Accessed 6 July 2017

122. ClinicalTrials.gov (2000) National Library of Medicine (US), Bethesda. Identifier NCT01861496. Phase I/II study to evaluate the safety and tolerability of LiPlaCis in patients with advanced or refractory tumours (LiPlaCis); 2013 May 1 [about 7 screens]. https://clinicaltrials.gov/ct2/ show/NCT01861496?term =LiPlaCis\&rank=1. Accessed 6 July 2017

123. Product (Promiti ${ }^{\circledR}$ Overview) (2017) LipoMedix. http://lipomedix.com/ Products/\%C2\%AEProduct-Promitil. Accessed 6 July 2017

124. ClinicalTrials.gov (2000) National Library of Medicine (US), Bethesda. Identifier NCT01705002. Intravenously administered pegylated liposomal mitomycin-C lipid-based prodrug (PROMITIL) in cancer patients with solid tumors; 2012 Oct 8 [about 9 screens]. https://clinicaltrials. gov/ct2/show/NCT01705002?term=PROMITIL\&rank=1. Accessed 6 July 2017

125. ClinicalTrials.gov (2000) National Library of Medicine (US), Bethesda. Identifier NCT01463072. Paclitaxel albumin-stabilized nanoparticle formulation in treating older patients with locally advanced or metastatic Breast Cancer; 2011 Oct 25 [about 6 screens]. https://clinicaltrials.gov/ ct2/show/NCT01463072?term=nanoparticle\%2C+cancer\&rank=6. Accessed 6 July 2017

126. Genexol ${ }^{\circledR}$ PM Injections. Samyang Biopharmaceuticals. https://www. samyangbiopharm.com/eng/ProductIntroduce/injection01. Accessed 4 July 2017

127. Young C, Schluep T, Hwang J, Eliasof S (2011) CRLX101 (formerly IT-101) a novel nanopharmaceutical of camptothecin in clinical development. Curr Bioact Compd 7(1):8-14 